NBER WORKING PAPER SERIES

\title{
NOMINAL RIGIDITIES AND THE DYNAMIC EFFECTS OF A SHOCK TO MONETARY POLICY
}

\author{
Lawrence J. Christiano \\ Martin Eichenbaum \\ Charles Evans
}

Working Paper 8403

http://www.nber.org/papers/w8403

\author{
NATIONAL BUREAU OF ECONOMIC RESEARCH \\ 1050 Massachusetts Avenue \\ Cambridge, MA 02138 \\ July 2001
}

The first two authors are grateful for the financial support of a National Science Foundation grant to the National Bureau of Economic Research. We would like to acknowledge helpful comments from Lars Hansen, Chris Sims and Mark Watson. We particularly want to thank Levon Barseghyan for his superb research assistance. The views expressed herein are those of the authors and not necessarily those of the National Bureau of Economic Research.

(C) 2001 by Lawrence J. Christiano, Martin Eichenbaum and Charles Evans. All rights reserved. Short sections of text, not to exceed two paragraphs, may be quoted without explicit permission provided that full credit, including $\odot$ notice, is given to the source. 
Nominal Rigidities and the Dynamic Effects of a Shock to Monetary Policy

Lawrence J. Christiano, Martin Eichenbaum and Charles Evans

NBER Working Paper No. 8403

July 2001

JEL No. E3, E4, E5

\begin{abstract}
We present a model embodying moderate amounts of nominal rigidities which accounts for the observed inertia in inflation and persistence in output. The key features of our model are those that prevent a sharp rise in marginal costs after an expansionary shock to monetary policy. Of these features, the most important are staggered wage contracts of average duration three quarters, and variable capital utilization.
\end{abstract}

Lawrence J. Christiano

Northwestern University, National Bureau of Economic Research, and Federal Reserve Banks of Chicago and Cleveland

Martin Eichenbaum

Northwestern University, National Bureau of Economic Research, and Federal Reserve Bank of Chicago

Charles Evans

Federal Reserve Bank of Chicago 


\section{Introduction}

This paper seeks to understand the observed inertial behavior of inflation and persistence in aggregate quantities. To this end, we formulate and estimate a dynamic, general equilibrium model which incorporates staggered wage and price contracts. We use our model to investigate what mix of frictions can account for the evidence of inertia and persistence. For this exercise to be well defined, we must characterize inertia and persistence precisely. We do so using estimates of the dynamic response of inflation and aggregate variables to a monetary policy shock. With this characterization, the question that we ask reduces to: 'Can models with moderate degrees of nominal rigidities generate inertial inflation and persistent output movements in response to a monetary policy shock?'1 Our answer to this question is, 'yes'.

The model that we construct has two key features. First, it embeds Calvo style nominal price and wage contracts. Second, the real side of the model incorporates three departures from the standard textbook one sector dynamic stochastic growth model. These are motivated by recent research on the determinants of consumption, asset prices, investment and productivity. The specific departures which we include are habit persistence in preferences for consumption, adjustment costs in investment and variable capital utilization.

Our key findings are as follows. First, the average duration of price and wage contracts in the estimated model is roughly 2 and 3 quarters, respectively. Despite the modest nature of these nominal rigidities, the model does a very good job of accounting quantitatively for the estimated response of the US economy to a policy shock. In addition to reproducing the dynamic response of inflation and output, the model also accounts for the delayed, humpshaped response in consumption, investment, profits, productivity and the weak response of the real wage. ${ }^{2}$ Second, the critical nominal friction in our model is wage contracts, not price contracts. A version of the model with only nominal wage rigidities does almost as well as the estimated model. In contrast, with only nominal price rigidities, the model performs very poorly. Consistent with existing results in the literature, this version of the model cannot generate persistent movements in output unless we assume price contracts of extremely long duration. ${ }^{3}$ The model with only nominal wage rigidities does not have this problem.

Third, we show that inference about nominal rigidities is sensitive to getting the real

\footnotetext{
${ }^{1}$ This is the same question that is the focus of a large and growing literature. See, for example, Chari, Kehoe and McGrattan (2000), Mankiw (2001), Rotemberg and Woodford (1999) and the references therein.

${ }^{2}$ In related work, Sbordone (2000) argues that, taking as given aggregate real variables, a model with staggered wages and prices does well at accounting for the time series properties of wages and prices.

${ }^{3}$ See for example Chari, Kehoe and McGrattan (2000).
} 
side of the model 'right'. 4 Estimated versions of the model which do not incorporate our departures from the standard growth model imply implausibly long price and wage contracts. Fourth, we find that if one only wants to match the inertia in inflation and persistence in output with moderate wage and price stickiness, then only variable capital utilization is required. To understand why this feature is so important note that in our model, firms set prices as a markup over marginal costs. The major components of marginal costs are wages and the rental rate of capital. By allowing the services of capital to increase after a positive monetary policy shock, variable capital utilization helps dampen the large rise in the rental rate of capital that would otherwise occur. This in turn dampens the rise in marginal costs and, hence, prices. The resulting inertia in inflation implies that the rise in nominal spending that occurs after a positive monetary policy shock produces a persistent rise in real output. Similar intuition explains why sticky wages play a critical role in allowing our model to explain inflation inertia and output persistence.

Finally, we find that our model embodies strong internal propagation mechanisms. For example, even in response to an iid shock in the growth rate of money, the model generates a large, persistent hump shaped response in aggregate output and an inertial response in inflation. More generally, the model implies that the effects of a shock to monetary policy on aggregate variables persist well beyond the effects of the shock on the interest rate and the growth rate of money.

We pursue a particular limited information econometric strategy to estimate and evaluate our model. The basic idea behind this strategy can be summarized as follows. We characterize monetary policy as a rule which expresses the interest rate as a function of aggregate economic variables and a monetary policy shock. Our assumptions about the shock imply a particular series of projection equations which can be exploited to estimate the dynamic effects of a monetary policy disturbance on aggregate economic variables. ${ }^{5}$ Our econometric strategy compares these projections in the model and in the data.

In our model, the projections correspond to the dynamic response of the economy to

\footnotetext{
${ }^{4}$ Other authors have also argued that inference about nominal rigidities can be distorted in important ways if the real side of the economy is misspecified. See for example Fuhrer (2000), McCallum and Nelson (1998) and Sims (1998). See also the interesting paper by Edge (2000), which incorporates habit formation, time-to-build capital, and investment adjustment costs into a Calvo-style sticky price model. She shows that these real perturbations substantially improve the performance of the Calvo model.

${ }^{5}$ A particularly simple example can be found in Chari, Kehoe and McGrattan (2000) and Cooley and Hansen (1989). They assume that the monetary policy shock is the error in a first order autoregressive representation for money growth. Under these conditions, the policy shock is the error in the projection of money growth on one lag of itself. The dynamic response of a variable to the shock is the projection of that variable on current and past values of the shock.
} 
a policy shock. Our model has the property that the projections are independent of the nature of the non-monetary shocks. ${ }^{6}$ This is an important advantage, since it allows us to avoid taking a stand on the nature of the non-monetary shocks. For convenience, we simply set the other shocks to zero. ${ }^{7}$ To obtain empirical estimates of the projections, we exploit the well-known result that vector autoregressions (VAR's) provide an excellent characterization of the second moment properties of the data. As such, we estimate a VAR for the key variables in our model economy and compute the projections implied by this representation. In practice, this amounts to computing standard impulse response functions to a particular orthogonalized innovation in the VAR. We stress the projection interpretation of our procedure in order to draw attention to the sense in which we are computing the same object in the model and in the data. ${ }^{8}$

It is worth contrasting our strategy with an alternative, perhaps more traditional, one. This alternative strategy focuses on the model's predictions for various second moments of the data, such as auto- and cross- correlations of different variables. While the advantages of this strategy are well known, they come at a cost. Since these types of second moments reflect the operation of all the shocks driving the economy, the model used in the analysis must incorporate all of these shocks too. So, the analyst must not just take a stand on precisely how monetary shocks enter the economy. The analyst must also take a stand on the nature of shocks to government spending, technology, money demand, preferences, etc. ${ }^{9}$ The advantage of the limited information strategy is that it allows us to learn about some aspects of the structure of the economy without taking a stand on these other shocks.

The remainder of this paper is organized as follows. In section 2 we briefly describe our estimates of how the US economy responds to a monetary policy shock. Section 3 displays our economic model. In Section 4 we discuss our econometric methodology. Our empirical results are presented in Section 5. Concluding comments are contained in section 6 .

\footnotetext{
${ }^{6}$ This is actually only true as an approximation. It is a feature of the linear policy rules we use to approximate the solution to the model. A maintained assumption of our analysis is that this approximation is reasonably accurate.

'This is not true for all models. For example, the signal extraction problem in Lucas' (1972) monetary misperception model implies that the response of the economy to a monetary policy shock depends sensitively on the nature of the other shocks. So, even if one is only interested in knowing the effects of a monetary policy shock in a monetary misperception model, one still cannot avoid taking a stand on the nature of the other shocks.

${ }^{8}$ Christiano, Eichenbaum and Evans (1998), Edge (2000) and Rotemberg and Woodford (1997) have also applied this strategy in the context of monetary policy shocks.

${ }^{9}$ See for example Chari, Christiano and Eichenbaum (1995), Ireland (1997), Kim (2000), and Leeper and Sims (1994). An extreme version of this strategy assumes that the only disturbances to the economy are monetary policy shocks (see Chari, Kehoe and McGrattan (2000).
} 


\section{The Consequences of a Monetary Policy Shock}

The starting point of our analysis is the following characterization of monetary policy:

$$
R_{t}=f\left(\Omega_{t}\right)+\varepsilon_{t}
$$

Here, $R_{t}$ is the Federal Funds rate, $f$ is a linear function, $\Omega_{t}$ is an information set, and $\varepsilon_{t}$ is the monetary policy shock. Our interpretation of (2.1) is that the Fed allows money growth to be whatever is necessary to guarantee that (2.1) holds. Our basic identifying assumption is that $\varepsilon_{t}$ is orthogonal to the elements in $\Omega_{t}$. Below, we describe the variables in $\Omega_{t}$ and elaborate on the interpretation of the orthogonality assumption.

We now briefly motivate our procedure for estimating the projection of economic variables on current and past $\varepsilon_{t}$ 's. In principle, there are two ways to estimate this projection, also known as an impulse response function. The first begins by estimating the $\varepsilon_{t}$ 's using the fitted residuals from a regression of $R_{t}$ on $\Omega_{t}$. The impulse response of a variable to the $\varepsilon_{t}$ 's is then estimated in a second-stage regression of the variable on current and past values of the fitted residuals. There are two difficulties with this approach: (i) to obtain several years' worth of responses, one must use up a substantial number of initial observations, thus reducing sample size; and (ii) the coefficients in the second-stage regression tend to be imprecisely estimated. We pursue an alternative approach based on a vector autoregression (VAR) fit to the vector of variables included in $\Omega_{t}$. VAR's are well known to provide an excellent summary of the second moment properties of the data. With this in mind, we estimate a VAR for the key variables in our model and then compute the projections implied by this representation. This is equivalent to the standard procedure for computing impulse response functions to a particular orthogonalized innovation in a VAR. Because the number of lags in a VAR is quite small in practice, this approach avoids the loss of initial observations in the first-stage regression discussed above. In addition, we expect that the structure imposed by the VAR leads to relatively precise estimates of the impulse response functions.

We now briefly describe the details of our VAR and of our identifying assumptions. Let $Y_{t}$ denote the vector of variables included in the analysis. We partition $Y_{t}$ as follows:

$$
Y_{t}=\left[\begin{array}{c}
Y_{1 t} \\
R_{t} \\
Y_{2 t}
\end{array}\right] .
$$

The vector, $Y_{1 t}$, is composed of the variables whose time $t$ elements are contained in $\Omega_{t}$, and are assumed to not respond contemporaneously to a monetary policy shock. The vector $Y_{2 t}$ consists of the time $t$ values of all the other variables in $\Omega_{t}$. In practice, the variables in $Y_{1 t}$ are real GDP, real consumption, the GDP deflator, real investment, the real wage, and labor 
productivity. The variables in $Y_{2 t}$ are real profits, the growth rate of M2, and the S\&P500 index, scaled by the consumer price index. All these variables, except money growth, have been logged. We measure the interest rate, $R_{t}$, using the Federal Funds rate.

The ordering of the variables in $Y_{t}$ embodies two key identifying assumptions. First, the variables in $Y_{1 t}$ are assumed to not respond contemporaneously to a monetary policy shock. Second, the time $t$ information set of the monetary authority consists of current and lagged values of the variables in $Y_{1 t}$ and only past values of the variables in $Y_{2 t}$. The model constructed in the next section incorporates both assumptions.

The VAR contains 4 lags of each variable and the sample period is $1965 \mathrm{Q} 3-1995 \mathrm{Q} 3$. $^{10}$ Ignoring the constant term, the VAR can be written as follows:

$$
Y_{t}=A_{1} Y_{t-1}+\ldots+A_{4} Y_{t-4}+C \eta_{t}
$$

where $C$ is a $10 \times 10$ lower triangular matrix with diagonal terms equal to unity, and $\eta_{t}$ is a 10-dimensional vector of zero-mean, serially uncorrelated shocks with diagonal variancecovariance matrix. Since there are six variables in $Y_{1 t}$, the monetary policy shock, $\varepsilon_{t}$, is the 7 th element of $\eta_{t}$. A positive shock to $\varepsilon_{t}$ corresponds to a contractionary monetary policy shock. We estimate the parameters $-A_{i}, i=1, \ldots, 4, C$, and the variance-covariance matrix of $\eta_{t}$ - using standard, least squares, methods. Using these parameter estimates, we compute the dynamic path of $Y_{t}$ following a one-standard-deviation shock in $\varepsilon_{t}$, setting initial conditions to zero. This path, which corresponds to the coefficients in the impulse response functions of interest, is invariant to the ordering of the variables within $Y_{1 t}$ and within $Y_{2 t}$ (see Christiano, Eichenbaum and Evans (1999).)

The impulse response functions of all variables in $Y_{t}$ are displayed in Figure 1. Lines marked ' + ' correspond to the point estimates. The shaded areas indicate $95 \%$ confidence intervals about the point estimates. ${ }^{11}$ The solid lines pertain to the properties of our structural model, which will be discussed in section 3. The results suggest that after an expansionary monetary policy shock there is a:

- hump-shaped, response of output, consumption and investment, with the peak effect occurring after about 1.5 years,

- hump-shaped response in inflation, with a peak response after about 2 years,

- fall in the interest rate for roughly one year,

- rise in profits, real wages and labor productivity, and

\footnotetext{
${ }^{10}$ This sample period is the same as in Christiano, Eichenbaum and Evans (1999).

${ }^{11}$ We use the method described in Sims and Zha (1999).
} 
- an immediate rise in the growth rate of money.

The robustness of the qualitative features of these findings to alternative identifying assumptions, alternative sample sub-periods and the use of monthly data is discussed in Christiano, Eichenbaum and Evans (1999).

\section{The Model Economy}

In this section we describe our model economy and display the problems solved by firms and households. In addition, we describe the behavior of financial intermediaries and the monetary and fiscal authorities.

\subsection{Final Good Firms}

At time $t$, a final consumption good, $Y_{t}$, is produced by a perfectly competitive firm. The firm does so by combining a continuum of intermediate goods, indexed by $j \in[0,1]$, using the technology

$$
Y_{t}=\left[\int_{0}^{1} Y_{j t^{\frac{1}{\lambda_{f}}}} d j\right]^{\lambda_{f}}
$$

where $1 \leq \lambda_{f}<\infty$, and $Y_{j t}$ denotes the time $t$ input of intermediate good $j$. Let $P_{t}$ and $P_{j t}$ denote the time $t$ price of the consumption good and intermediate good $j$, respectively. Profit maximization implies the Euler equation

$$
\left(\frac{P_{t}}{P_{j t}}\right)^{\frac{\lambda_{f}}{\lambda_{f}-1}}=\frac{Y_{j t}}{Y_{t}} .
$$

According to (3.2), the demand for intermediate good $j$ is a decreasing function of the relative price of that good and an increasing function of aggregate output, $Y_{t}$. Integrating (3.2) and imposing (3.1), we obtain the following relationship between the price of the final good and the price of the intermediate good:

$$
P_{t}=\left[\int_{0}^{1} P_{j t}^{\frac{1}{1-\lambda_{f}}} d j\right]^{\left(1-\lambda_{f}\right)} .
$$




\subsection{Intermediate Good Firms}

Intermediate good $j \in(0,1)$ is produced by a monopolist who uses the following technology:

$$
Y_{j t}= \begin{cases}k_{j t}^{\alpha} L_{j t}^{1-\alpha}-\phi & \text { if } k_{j t}^{\alpha} L_{j t}^{1-\alpha} \geq \phi \\ 0, & \text { otherwise }\end{cases}
$$

where $0<\alpha<1$. Here, $L_{j t}$ and $k_{j t}$ denote time $t$ labor and capital services used to produce the $j^{\text {th }}$ intermediate good. Also, $\phi>0$ denotes the fixed cost of production. We rule out entry and exit into the production of intermediate good $j$. In the empirical analysis, $\phi$ is set to guarantee that profits are zero in steady state. This is consistent with Basu and Fernald (1994), Hall (1988), and Rotemberg and Woodford (1995), who argue that economic profits are close to zero on average.

Intermediate firms rent capital and labor in perfectly competitive factor markets. Profits are distributed to households at the end of each time period. Let $R_{t}^{k}$ and $W_{t}$ denote the nominal rental rate on capital services and the wage rate, respectively. Workers must be paid in advance of production. As a result, the $j^{t h}$ firm must borrow its wage bill, $W_{t} L_{j t}$, from the financial intermediary at the beginning of the period. Repayment occurs at the end of time period $t$ at the gross interest rate, $R_{t}$. Consequently, the firm's total time $t$ costs are given by $R_{t} W_{t} L_{j t}+R_{t}^{k} k_{j t}$. The firm's real marginal cost is given by:

$$
s_{t}=\left(\frac{1}{1-\alpha}\right)^{1-\alpha}\left(\frac{1}{\alpha}\right)^{\alpha}\left(r_{t}^{k}\right)^{\alpha}\left(w_{t} R_{t}\right)^{1-\alpha} .
$$

where $r_{t}^{k}=R_{t}^{k} / P_{t}$ and $w_{t}=W_{t} / P_{t}$. The firm's time $t$ profits are:

$$
\left[\frac{P_{j t}}{P_{t}}-s_{t}\right] P_{t} Y_{j t}
$$

where $P_{j t}$ is firm $j$ 's price.

We assume that firms set prices according to a variant of the mechanism spelled out in Calvo (1983). In each period, a firm faces a constant probability, $1-\xi_{p}$, of being able to reoptimize its nominal price. The ability to reoptimize its price is independent across firms and time. If a firm can reoptimize its price, it does so before the realization of the time $t$ growth rate of money. We consider two specifications of what happens if a firm cannot reoptimize its price. In each case prices are reset automatically according to a simple rule. The first specification, which corresponds to the standard one used in the literature, is

$$
P_{j t}=\bar{\pi} P_{j, t-1}
$$


where $\bar{\pi}$ is the steady state, gross rate of inflation (see Erceg, Henderson and Levin, 2000 and Yun, 1996. $)^{12}$ We refer to (3.6) as the static price updating scheme.

The second specification is motivated by claims in the literature that the first specification does not generate sufficient inertia in inflation. In this specification, firm $j$ must set its price according to

$$
P_{j t}=\pi_{t-1} P_{j, t-1}
$$

Below, we explain the theoretical and quantitative implications of this dynamic price-updating scheme.

We interpret the Calvo price-setting mechanism as capturing firms' response to various costs of changing prices. The basic idea is that in the presence of these costs firms fully optimize prices only periodically, and follow simple rules for changing their prices at other times. The type of costs we have in mind are those associated with optimization (e.g., costs associated with information gathering, decision making, negotiation and communication). These costs are different from menu costs, which apply to all price changes. Zbaracki, Ritson, Levy, Dutta and Bergen (2000) provide some microeconomic evidence that costs associated with reoptimization are much more important than menu costs.

In what follows we focus, for convenience, on specification (3.7). Let $\tilde{P}_{t}$ denote the value of $P_{j t}$ set by a firm that can reoptimize at time $t$. Our notation does not allow $\tilde{P}_{t}$ to depend on $j$. We do this in anticipation of the well known result that in models like ours, all firms who can reoptimize their price at time $t$ choose the same price (see Woodford, 1996) and Yun, 1996).

The firm chooses $\tilde{P}_{t}$ to maximize:

$$
E_{t-1} \sum_{l=\mathbf{0}}^{\infty}\left(\beta \xi_{p}\right)^{l} v_{t+l}\left[\tilde{P}_{t} X_{t l}-s_{t+l} P_{t+l}\right] Y_{j, t+l}
$$

subject to $(3.2),(3.5)$ and

$$
X_{t l}=\left\{\begin{array}{cc}
\pi_{t} \times \pi_{t+1} \times \cdots \times \pi_{t+l-1} & \text { for } l \geq 1 \\
1 & l=0
\end{array} .\right.
$$

In (3.8), $v_{t}$ is the marginal value of a dollar to the household, which is treated as exogenous by the firm. Later, we show that the value of a dollar, in utility terms, is constant across households. Also, $E_{t-1}$ denotes the expectations operator, conditioned on lagged growth rates of money, $\mu_{t-l}, l \geq 1$. This specification of the information set captures our assumption that the firm chooses $\tilde{\widetilde{P}}_{t}$ before the realization of the time $t$ growth rate of money.

\footnotetext{
${ }^{12}$ Others, like Dotsey, King and Wolman (1999), and Woodford (1996) assume $P_{j t}=P_{j, t-1}$.
} 
To understand (3.8), note that $\tilde{P}_{t}$ influences firm $j$ 's profits only as long as it cannot reoptimize its price. The probability that this happens for $l$ periods is $\left(\xi_{p}\right)^{l}$, in which case $P_{j, t+l}=\tilde{P}_{t} X_{t l}$. The presence of $\left(\xi_{p}\right)^{l}$ in $(3.8)$ has the effect of isolating future realizations of idiosyncratic uncertainty in which $\tilde{P}_{t}$ continues to affect the firm's profits.

The first order condition associated with the firm's choice of $\tilde{P}_{t}$ is:

$$
E_{t-1} \sum_{l=0}^{\infty}\left(\beta \xi_{p}\right)^{l} v_{t+l} Y_{j, t+l}\left[\tilde{P}_{t} X_{t l}-\lambda_{f} P_{t+l} s_{t+l}\right]=0 .
$$

When $\xi_{p}=0,(3.10)$ reduces to the familiar condition that the firm sets its price, $\tilde{P}_{t}$, equal to a markup over expected marginal cost, $P_{t} s_{t}$, conditional on information at $t-1$. When $\xi_{p}>0$, the firm sets $\tilde{P}_{t}$ to a markup over the weighted average of marginal costs over time.

To gain further intuition into the firm's problem, it is convenient to linearize (3.10) about the steady state values of the relevant variables:

$$
\hat{\tilde{p}}_{t}=E_{t-1}\left[\hat{s}_{t}+\sum_{l=1}^{\infty}\left(\beta \xi_{p}\right)^{l}\left(\hat{s}_{t+l}-\hat{s}_{t+l-1}\right)+\sum_{l=1}^{\infty}\left(\beta \xi_{p}\right)^{l}\left(\hat{\pi}_{t+l}-\hat{\pi}_{t+l-1}\right)\right] .
$$

Here, $\tilde{p}_{t}=\tilde{P}_{t} / P_{t}$, and a hat over a variable indicates the percent deviation from its steady state value. That is, $\hat{\tilde{p}}_{t}=\left(\tilde{p}_{t}-\tilde{p}\right) / \tilde{p}$, where a variable without a hat or a subscript indicates its nonstochastic steady state value. ${ }^{13}$ Several features of (3.11) are worth noting. First, if inflation and real marginal cost are expected to remain at their time $t$ levels, then the firm sets $\hat{\tilde{p}}_{t}=E_{t-1} \hat{s}_{t}$. Second, suppose the firm expects real marginal costs to be higher in the future than at time $t$. Anticipating those future marginal costs, the firm sets $\hat{\tilde{p}}_{t}$ higher than $E_{t-1} \hat{s}_{t}$. It does so because it understands that it may not be able to raise its price when those higher marginal costs materialize. We refer to this type of forward looking behavior as 'front loading'. Third, suppose firms expect inflation in the future to rise above $E_{t-1} \hat{\pi}_{t}$. The one period lag in the dynamic price-setting rule, (3.7), implies that the firm's relative price would fall. To compensate, the firm front loads expected future changes in the inflation rate into $\hat{\tilde{p}}_{t}$.

Suppose that instead of adopting (3.7) we had proceeded as in the literature, by assuming the static price-updating scheme, (3.6). Then, the analog expression to (3.11) is:

$$
\hat{\tilde{p}}_{t}=E_{t-1}\left[\hat{s}_{t}+\sum_{l=1}^{\infty}\left(\beta \xi_{p}\right)^{l}\left(\hat{s}_{t+l}-\hat{s}_{t+l-1}\right)+\sum_{l=1}^{\infty}\left(\beta \xi_{p}\right)^{l} \hat{\pi}_{t+l}\right] .
$$

\footnotetext{
${ }^{13}$ By 'nonstochastic' we mean only that the aggregate shock is held at its unconditional mean. The idiosyncratic shocks associated with Calvo pricing are non-trivial random variables in the nonstochastic version of the model.
} 
With this specification, the firm front loads expected future changes in the price level, rather than the inflation rate. To clarify the nature of front loading under the different updating schemes, imagine $E_{t-1} \hat{\pi}_{t}=E_{t-1} \hat{\pi}_{t+1}>0$. With specification (3.7), $P_{j, t+1}$ rises by the amount of inflation at time $t$, so there is no need to front load the expected inflation into $\hat{\tilde{p}}_{t}$. In contrast, with the standard specification (3.6), $P_{j, t+1}$ does not adjust in response to $\hat{\pi}_{t}$, so the firm has an incentive to front load $E_{t-1} \hat{\pi}_{t+1}$ directly into $\hat{\tilde{p}}_{t}$.

It follows from well-known results in the literature that (3.3) can be expressed as: ${ }^{14}$

$$
P_{t}=\left[\left(1-\xi_{p}\right)\left(\tilde{P}_{t}\right)^{\frac{1}{1-\lambda_{f}}}+\xi_{p}\left(\pi_{t-1} P_{t-1}\right)^{\frac{1}{1-\lambda_{f}}}\right]^{1-\lambda_{f}} .
$$

Dividing by $P_{t}$, linearizing and rearranging, we obtain:

$$
\hat{\tilde{p}}_{t}=\frac{\xi_{p}}{1-\xi_{p}}\left(\hat{\pi}_{t}-\hat{\pi}_{t-1}\right)
$$

Relations (3.11) and (3.14) imply:

$$
\hat{\pi}_{t}=\frac{1}{1+\beta} \hat{\pi}_{t-1}+\frac{\beta}{1+\beta} E_{t-1} \hat{\pi}_{t+1}+\frac{\left(1-\beta \xi_{p}\right)\left(1-\xi_{p}\right)}{(1+\beta) \xi_{p}} E_{t-1} \hat{s}_{t} .
$$

Solving this for $\hat{\pi}_{t}-\hat{\pi}_{t-1}$, imposing $E_{t-1} \beta^{j}\left(\hat{\pi}_{t+j}-\hat{\pi}_{t+j-1}\right) \rightarrow 0$, we obtain:

$$
\hat{\pi}_{t}-\hat{\pi}_{t-1}=\frac{\left(1-\beta \xi_{p}\right)\left(1-\xi_{p}\right)}{\xi_{p}} E_{t-1} \sum_{j=0}^{\infty} \beta^{j} \hat{s}_{t+j}
$$

The analog expressions, obtained using the static price-updating scheme, (3.6), are: ${ }^{15}$

$$
\begin{gathered}
\hat{\pi}_{t}=\beta E_{t-1} \hat{\pi}_{t+1}+\frac{\left(1-\beta \xi_{p}\right)\left(1-\xi_{p}\right)}{\xi_{p}} E_{t-1} \hat{s}_{t} . \\
\hat{\pi}_{t}=\frac{\left(1-\beta \xi_{p}\right)\left(1-\xi_{p}\right)}{\xi_{p}} E_{t-1} \sum_{j=0}^{\infty} \beta^{j} \hat{s}_{t+j} .
\end{gathered}
$$

To motivate our interest in the dynamic price-updating scheme, consider the reduced form for inflation, (3.17), implied by the standard, static price-updating scheme. Authors

\footnotetext{
${ }^{14}$ See, for example, Calvo (1983).

${ }^{15}$ The analog expression to (3.14) is $\widehat{\tilde{p}}_{t}=\frac{\xi_{p}}{1-\xi_{p}} \hat{\pi}_{t}$.
} 
like Fuhrer and Moore (1995) and Gali and Gertler (1999) argue that the absence of lagged inflation in (3.17) prevents the model from being able to account for the observed degree of serial correlation in inflation. These authors modify the Calvo framework in non-trivial ways to induce a lagged inflation term into (3.17). ${ }^{16}$ As can be seen from (3.15), the dynamic price-updating scheme provides an alternative way to accomplish this. ${ }^{17}$ Interestingly, the coefficients on lagged and future inflation in (3.15) virtually coincide with the values estimated by Gali and Gertler (1999) and the value of $1 / 2$ often assumed in the literature. ${ }^{18}$

We conclude this subsection by emphasizing three results. First, under either specification $\hat{\pi}_{t}$ does not respond to a period $t$ monetary policy shock. So, the model is consistent with a key identifying restriction in our empirical work: the price level does not respond contemporaneously to a monetary policy shock. Second, under either specification inflation depends on expected future marginal costs. Relation (3.5) implies that marginal cost is an increasing function of the wage rate, the rental rate on capital and the interest rate. In section 2 we found that inflation responds only slowly to a monetary shock. Putting these observations together, we anticipate that our econometric estimates will place substantial emphasis on the features of our model that mute the expected future responses of $r_{t}^{k}, w_{t}$ and $R_{t}$ to a monetary policy shock. Third, for any given process describing $\hat{s}_{t}$ relations (3.16) and (3.18) imply that inflation will be more inertial under the dynamic price-updating scheme than under the static price-updating scheme.

\footnotetext{
${ }^{16}$ Another concern has been raised with the Calvo pricing scheme. Fuhrer and Moore (1995) and others argue that the standard formulation counterfactually implies that inflation leads output. However, as Gali and Gertler (1999) point out, this rests on a specification in which $\hat{s}_{t}$ is measured by the output gap. Gali and Gertler (1999) point out that this criticism does not apply to models like ours in which $\hat{s}_{t}$ corresponds to real marginal cost. In addition, they provide evidence in support of specifications like this.

${ }^{17}$ Ball (1994) and Mankiw (2000) and others have raised another objection to Calvo-style sticky price models: a credible disinflation is associated with an expansion in economic activity. This criticism is based on a version of (3.17) in which a measure of the output gap appears instead of marginal costs, $\hat{s}$. It is not clear that their criticism applies to our model. First, we incorporate marginal costs and not the output gap. Second, our measure of marginal cost includes the interest rate. In our model, we conjecture that a credible dinsinflation would be associated with a transitory $r$ ise in the interest rate and therefore a rise in marginal costs. So, it is possible that our model is not subject to this criticism. This is an interesting issue which we leave to future research.

${ }^{18}$ See Casares and McCallum (2000), Mankiw (2001) and Walsh (1998, p. 224-225).
} 


\subsection{Households}

There is a continuum of households, indexed by $j \in(0,1)$. The $j^{\text {th }}$ household makes a sequence of decisions during each period. First, it makes its consumption decision, its capital accumulation decision, and it decides how many units of capital services to supply. Second, it purchases securities whose payoffs are contingent upon whether it can reoptimize its wage decision. Third, it sets its wage rate after finding out whether it can reoptimize or not. Fourth, it receives a lump-sum transfer from the monetary authority. Finally, it decides how much of its financial assets to hold in the form of deposits with a financial intermediary and how much to hold in the form of cash.

Since the uncertainty faced by the household over whether it can reoptimize its wage is idiosyncratic in nature, households work different amounts and earn different wage rates. So, in principle they are also heterogeneous with respect to consumption and asset holdings. A straightforward extension of arguments in Erceg, Henderson and Levin (2000) and Woodford (1996), establish that the existence of state contingent securities ensures that in equilibrium households are homogeneous with respect to consumption and asset holdings. Reflecting this result, our notation assumes that households are homogeneous with respect to consumption and asset holdings, and heterogeneous with respect to the wage rate that they earn and hours worked.

The preferences of the $j^{\text {th }}$ household are given by:

$$
E_{t-1}^{j} \sum_{l=0}^{\infty} \beta^{l-t}\left[u\left(c_{t+l}-b c_{t+l-1}\right)-z\left(h_{j, t+l}\right)+v\left(q_{t+l}\right)\right],
$$

where $E_{t-1}^{j}$ is the expectation operator, conditional on aggregate and household $j$ idiosyncratic information up to, and including, time $t-1 ; c_{t}$ denotes time $t$ consumption; $h_{j t}$ denotes time $t$ hours worked; $q_{t} \equiv Q_{t} / P_{t}$ denotes real cash balances; and $Q_{t}$ denotes nominal cash balances.

When $b>0,(3.19)$ allows for habit formation in consumption preferences. Authors such as Fuhrer (2000), and McCallum and Nelson (1998) have argued that this is important for understanding the monetary transmission mechanism. One way to motivate their argument is to recall that, according to our estimates, a positive monetary policy shock leads to a persistent decline in the real interest rate and a hump-shaped rise in consumption. A model with standard, time-separable preferences cannot be made consistent with this pattern. This is because household optimization implies that a low real interest rate is associated with high current consumption relative to the future. But, according to our estimates, after a monetary policy shock current consumption is low relative to the future. A model with habit persistence overturns the implication of standard models because in effect it replaces 
the level of consumption with its growth rate in the utility function. So, a low real interest rate is associated with high current consumption growth relative to the future - as in the data.

The household's asset evolution equation is given by:

$$
\begin{aligned}
M_{t+1}= & R_{t}\left[M_{t}-Q_{t}+\left(\mu_{t}-1\right) M_{t}^{a}\right]+A_{j, t}+Q_{t}+W_{j, t} h_{j, t} \\
& +R_{t}^{k} u_{t} \bar{k}_{t}+D_{t}-P_{t}\left(i_{t}+c_{t}+a\left(u_{t}\right) \bar{k}_{t}\right) .
\end{aligned}
$$

Here, $M_{t}$ is the household's beginning of period $t$ stock of money, $W_{j, t} h_{j, t}$ is time $t$ labor income. In addition, $\bar{k}_{t}, D_{t}$ and $A_{j, t}$ denote, respectively, the physical stock of capital, firm profits and the net cash inflow from participating in state-contingent securities at time $t$. The variable $\mu_{t}$ represents the gross growth rate of the economy-wide per capita stock of money, $M_{t}^{a}$. The quantity, $\left(\mu_{t}-1\right) M_{t}^{a}$ is a lump-sum payment made to households by the monetary authority. The quantity, $M_{t}-P_{t} q_{t}+\left(\mu_{t}-1\right) M_{t}^{a}$, is deposited by the household with a financial intermediary, where it earns the gross nominal rate of interest, $R_{t}$.

The remaining terms in (3.20), aside from $P_{t} c_{t}$, pertain to the stock of installed capital, which we assume is owned by the household. The household's stock of capital evolves according to:

$$
\bar{k}_{t+1}=(1-\delta) \bar{k}_{t}+F\left(i_{t}, i_{t-1}\right) .
$$

Here, $\delta$ denotes the physical rate of depreciation and $i_{t}$ denotes time $t$ purchases of investment goods. The function, $F$, summarizes the technology which transforms current and past investment into installed capital for use in the following period. We discuss the properties of $F$ below.

Capital services, $k_{t}$, are related to the physical stock of capital by

$$
k_{t}=u_{t} \bar{k}_{t}
$$

Here, $u_{t}$ denotes the utilization rate of capital, which we assume is set by the household. ${ }^{19}$ In (3.20), $R_{t}^{k} u_{t} \bar{k}_{t}$ represents the household's earnings from supplying capital services. The increasing, convex function, $a\left(u_{t}\right) \bar{k}_{t}$, denotes the cost, in units of consumption goods, of setting the utilization rate to $u_{t}$. Our motivation for allowing capital services to be elastic is two-fold. First, it damps movements in marginal costs by reducing fluctuations in the rental rate of capital. Second, it reduces the fall in labor productivity that would otherwise occur

\footnotetext{
${ }^{19}$ Our assumption that households make the capital accumulation and utilization decisions is a matter of convenience. At the cost of a more complicated notation, we could work with an alternative decentralization scheme in which firms make these decisions.
} 
after a positive monetary policy shock. ${ }^{20}$

In the remainder of this section, we briefly discuss the first order conditions of the household. The first order condition for $c_{t}$ is:

$$
E_{t-1} u_{c, t}=E_{t-1} \psi_{t}
$$

where $\psi_{t}=v_{t} P_{t}$, and $v_{t}$ is the value of a dollar to the household. The variable, $v_{t}$, is the multiplier on (3.20) in the Lagrangian representation of the household problem. It is easy to verify that $v_{t}$ is a function of the current period realization of $\mu_{t}$. In addition, $u_{c, t}$ is the realized value of the marginal utility of consumption at date $t$ :

$$
u_{c, t}=\frac{\partial u\left(c_{t}-b c_{t-1}\right)}{\partial c_{t}}-b E_{t} \frac{\partial u\left(c_{t+1}-b c_{t}\right)}{\partial c_{t}} .
$$

Equation (3.22) implies that in the absence of uncertainty, $\psi_{t}$ would be the marginal utility of consumption.

The first order condition for $M_{t+1}$ is given by:

$$
\psi_{t}=\beta E_{t} \psi_{t+1} \frac{R_{t+1}}{\pi_{t+1}}, \pi_{t+1}=\frac{P_{t+1}}{P_{t}} .
$$

This equation implies that the value of one dollar in the current period is equal to the present discounted value of the dollars one obtains by depositing a dollar in next period's financial market.

\subsubsection{The Wage Decision}

As in Erceg, Henderson and Levin (2000), we assume that the household is a monopoly supplier of a differentiated labor service, $h_{j t}$. It sells this service to a representative, competitive firm which transforms it into an aggregate labor input, $L_{t}$, using the following technology:

$$
L_{t}=\left[\int_{0}^{1} h_{j t}^{\frac{1}{\lambda_{w}}} d j\right]^{\lambda_{w}} .
$$

\footnotetext{
${ }^{20}$ For both these effects to be operative, $u_{t}$ must rise in the period after an expansionary monetary policy shock. To help generate this result, it is useful to assume that the cost of varying capital utilization takes the form of lost consumption goods. If, for example, the cost were a higher capital depreciation rate, then $u_{t}$ could actually fall after an expansionary monetary policy shock. This is because in the presence of investment adjustment costs the shadow value of installed capital rises after a positive monetary shock. This would increase the cost of utilizing capital.
} 
The demand curve for $h_{j t}$ is given by:

$$
h_{j t}=\left(\frac{W_{t}}{W_{j t}}\right)^{\frac{\lambda_{w}}{\lambda_{w}-1}} L_{t}, 1 \leq \lambda_{w}<\infty
$$

where $W_{t}$ is the aggregate wage rate, i.e., the price of $L_{t}$, which is related to individual household wages, $W_{j t}$, via the relationship:

$$
W_{t}=\left[\int_{0}^{1}\left(W_{j t}\right)^{\frac{1}{1-\lambda w}} d j\right]^{1-\lambda_{w}} .
$$

The household takes $L_{t}$ and $W_{t}$ as given.

Households set their wage rate according to a variant of the mechanism used to model price setting by firms. In each period, a household faces a constant probability, $1-\xi_{w}$, of being able to reoptimize its nominal wage. The ability to reoptimize is independent across households and time. We consider two specifications of what happens if a household cannot reoptimize its wage. The first specification corresponds to the standard one used in the literature, according to which

$$
W_{j t}=\bar{\pi} W_{j, t-1} \text {. }
$$

In the second specification, the $j^{t h}$ household must set its wage according to:

$$
W_{j, t}=\pi_{t-1} W_{j, t-1}
$$

Proceeding as in our discussion of intermediate good firms, we focus on specification (3.28). Let $\tilde{W}_{t}$ denote the value of $W_{j t}$ set by a household that can reoptimize its wage rate at time $t$. Our notation does not allow $\tilde{W}_{t}$ to depend on $j$. This is because all households that can reoptimize their wage choose the same wage. ${ }^{21}$ The first order condition associated with $\tilde{W}_{t}$ is:

$$
E_{t-1} \sum_{l=\mathbf{0}}^{\infty}\left(\xi_{w} \beta\right)^{l} h_{j, t+l} \psi_{t+l}\left[\frac{\tilde{W}_{t} X_{t l}}{P_{t+l}}-\lambda_{w} \frac{z_{h, t+l}}{\psi_{t+l}}\right]=0
$$

where, $X_{t, l}$ is defined in (3.9). To understand (3.29), note that $\tilde{W}_{t}$ influences household utility only as long as it cannot reoptimize its wage rate. The probability that this happens for $l$ periods is $\left(\xi_{w}\right)^{l}$, in which case the household's actual wage rate is $\tilde{W}_{t} X_{t l}$. The presence of $\left(\xi_{w}\right)^{l}$ in (3.29) has the effect of isolating future realizations of idiosyncratic uncertainty where $\tilde{W}_{t}$ continues to affect the household's utility.

\footnotetext{
${ }^{21}$ See the Appendix for a proof. This result mirrors results in Erceg, Henderson, and Levin (2000) and Woodford (1996).
} 
Note that when $\xi_{w}=0,(3.29)$ reduces to:

$$
\frac{\tilde{W}_{t}}{P_{t}}-\lambda_{w} \frac{z_{h, t}}{E_{t-1} u_{c, t}}=0 .
$$

Here, we have taken into account (3.22), and the fact that $\tilde{W}_{t}, h_{j, t}, z_{h, t}, P_{t}$ are not functions of the period $t$ realization of money growth. According to (3.30), the household sets its real wage equal to a constant markup, $\lambda_{w}$, over the expected marginal rate of substitution between consumption and leisure. Roughly speaking, (3.29) implies that when $\xi_{w}>0$, the household sets a weighted average of (3.30) over time to zero.

\subsubsection{Real Balances}

The household's first order condition for $Q_{t}$ is:

$$
v^{\prime}\left(q_{t}\right)+\psi_{t}=\psi_{t} R_{t} .
$$

This expression holds for each possible realization of the current period money growth rate because the cash balance decision is made after the current period money growth rate is realized. According to (3.31) the marginal utility of a dollar allocated to cash balances must equal the marginal utility of a dollar allocated to the financial intermediary. Relation (3.31) is the money demand equation in our model.

\subsubsection{Investment}

The first order conditions for $\bar{k}_{t+1}$ and $i_{t}$ imply

$$
E_{t-1} \psi_{t}=\beta E_{t-1} \psi_{t+1}\left[\frac{u_{t+1} r_{t+1}^{k}-a\left(u_{t+1}\right)+P_{k^{\prime}, t+1}(1-\delta)}{P_{k^{\prime}, t}}\right],
$$

and:

$$
E_{t-1} \psi_{t}=E_{t-1}\left[\psi_{t} P_{k^{\prime}, t} F_{1, t}+\beta \psi_{t+1} P_{k^{\prime}, t+1} F_{2, t+1}\right] .
$$

Here, $F_{j, t}$ is the partial derivative of $F\left(i_{t}, i_{t-1}\right)$ with respect to its $j^{\text {th }}$ argument, $j=1,2$. Also, $P_{k^{\prime}, t}$ is the shadow value, in consumption units, of a unit of $\bar{k}_{t+1}$ as of the time that the period $t$ investment and capital utilization decisions are made. It is what the price of installed capital would be if there were a market for $\bar{k}_{t+1}$ at the beginning of period $t$.

To understand the Euler equation for $\bar{k}_{t+1}$, note that the left side of (3.32) is the marginal cost of spending one unit of consumption on $\bar{k}_{t+1}$. The right side is the return to this investment. The object in square brackets is the rate of return on capital, in units of consumption goods. The other term converts the return into marginal utility units. 
To understand the Euler equation for $i_{t}$, note that the left side of (3.33) is the marginal cost of a unit of investment goods. Here we use the fact that the price of investment goods in terms of consumption is unity. To understand the right side of (3.33), note that an extra unit of investment goods produces $F_{1, t}$ extra units of $\bar{k}_{t+1}$. The value of these goods, in utility terms, is $P_{k^{\prime}, t} F_{1, t} E_{t-1} \psi_{t}$. An increase in $i_{t}$ also affects the quantity of installed capital produced in the next period by $F_{2, t+1}$. The last term in (3.33) measures the utility value of these additional capital goods.

We now briefly discuss the motivation for incorporating adjustment costs into the analysis. According to our estimates in section 2, after a positive monetary shock the real rate of interest, $R_{t} / \pi_{t+1}$, drops for several quarters. An empirically plausible monetary model should reproduce this observation. Such a model is also likely to imply that the rate of return on capital falls with $R_{t} / \pi_{t+1}$. Now, suppose there were no adjustment costs, i.e., $P_{k^{\prime}, t}=P_{k^{\prime}, t+1}=1$. Leaving aside movements in the markup and in $u_{t}$, this could only be accomplished by a fall in the marginal product of capital. This in turn requires a surge in investment. This is what we found in practice, even though the markup and $u_{t}$ are free to vary. In our numerical simulations, we found that the surge in investment and output is counterfactually large (see also Chari, McGrattan and Kehoe, 2000).)

The functional form for $F$ in (3.21) that we adopt is motivated by our empirical finding that investment exhibits a hump-shaped response to a monetary policy shock. Our specification for $F$, which penalizes the change in $i_{t}$, is a straightforward way to accommodate this. ${ }^{22}$

${ }^{22}$ Other authors, such as Chari, Kehoe and McGrattan (2000) and McCallum and Nelson (1998) adopt specifications which penalize the level of investment. In practice we found that it is difficult to account for the hump-shape response of investment with the latter specification. This finding is the outcome of numerical experiments in which we adopted the following specification for the capital accumulation technology:

$$
\bar{k}_{t+1} \leq Q\left((1-\delta) \bar{k}_{t}, i_{t}\right),
$$

where

$$
Q(y, z)=\left[a_{1} y^{\psi}+a_{2} z^{\psi}\right]^{1 / \psi},
$$

for $\psi \leq 1$. Here, $y$ denotes previously installed capital after depreciation and $z$ denotes new investment goods. The scalars $a_{1}, a_{2}>0$ were chosen to guarantee that $Q_{y}=Q_{z}=1$ in nonstochastic steady state. When $\psi=1$, the above technology corresponds to the conventional linear capital accumulation equation. In the case of adjustment costs, $\psi<1$, the marginal product of new investment goods is decreasing in the flow of investment. This technology has just the one free parameter, $\psi$. We found that for a large range of settings of $\psi$ our model has the implication that the investment impact of a positive monetary policy shock is greatest in the period when investment can first respond (i.e., the period after the monetary policy shock). 


\subsubsection{Capital Utilization}

The Euler equation associated with household's capital utilization decision is:

$$
E_{t-1} \psi_{t}\left[r_{t}^{k}-a^{\prime}\left(u_{t}\right)\right]=0
$$

According to this expression, the expected marginal benefit of raising utilization must equal the associated expected marginal cost. After linearizing this expression about nonstochastic steady state (see the Appendix), we obtain:

$$
E_{t-1}\left[\hat{r}_{t}^{k}-\sigma_{a} \hat{u}_{t}\right]=0
$$

Here, $\sigma_{a}$ denotes $a^{\prime \prime} / a^{\prime}$, and $a^{\prime}, a^{\prime \prime}$ denote the first and second derivatives of $a$, evaluated in steady state, respectively. ${ }^{23}$ From this we can see that for small values of $\sigma_{a}, E_{t} \hat{r}_{t+j}^{k}=0$ for $j>1$. Recall that $s_{t+j}$ is an increasing function of $r_{t+j}^{k}$ (see (3.5)). So, allowing for capital utilization and a low value of $\sigma_{a}$ helps mute the response of marginal cost and inflation to a monetary policy shock (see (3.16) and (3.18)).

\subsection{Monetary and Fiscal Policy}

Recall that in our empirical work we represent monetary policy by (2.1). As we discuss there, we interpret this rule as meaning that the monetary authority allows $\mu_{t}=M_{t+1} / M_{t}$ to adjust in a way which ensures that $(2.1)$ holds. This in turn requires that $\mu_{t}$ respond in a particular way to the current and past values of all the shocks hitting the economy. Since the only shock we are considering is a shock to monetary policy, the representation of monetary policy that we adopt in our model is given by:

$$
\mu_{t}=\mu+\theta_{0} \varepsilon_{t}+\theta_{1} \varepsilon_{t-1}+\theta_{2} \varepsilon_{t-2}+\ldots
$$

Here, $\mu$ denotes the mean growth rate of money and $\theta_{j}$ is the response of $E_{t} \mu_{t+j}$ to a time $t$ monetary policy shock. Finally, we assume that the government has access to lump sum taxes and pursues a Ricardian fiscal policy. Under this type of policy, the details of tax policy have no impact on inflation and other aggregate economic variables. As a result, we need not specify the details of fiscal policy. ${ }^{24}$

\footnotetext{
${ }^{23}$ Here, we have used the fact that we impose $r^{k}=a^{\prime}$, where $r^{k}$ denotes the rental rate on capital in steady state.

${ }^{24}$ See Sims (1994) or Woodford (1994) for a further discussion.
} 


\subsection{Loan Market Clearing, the Resource Constraint and Equilibrium}

Financial intermediaries receive $M_{t}-Q_{t}$ from households and a transfer, $\left(\mu_{t}-1\right) M_{t}$ from the monetary authority. Our notation here reflects the equilibrium condition, $M_{t}^{a}=M_{t}$. Financial intermediaries lend all of their money to intermediate good firms, which use the funds to pay for $L_{t}$. Loan market clearing requires

$$
W_{t} L_{t}=\mu_{t} M_{t}-Q_{t}
$$

We can use this equation, together with the household's money demand equation, (3.31), to understand how our model accounts for the estimated negative response of the interest rate to a positive monetary policy shock. In our model, an increase in the money supply must be absorbed by households. This is because the demand for money by firms, $W_{t} L_{t}$, does not respond to a policy shock. This reflects our assumption that consumption, investment and capital utilization are set prior to a monetary shock. so that $L_{t}$ is predetermined. Since the $W_{j t}$ 's do not respond to a monetary policy shock, it follows from (3.26) that $W_{t}$ is also predetermined. From (3.37) it follows that a period $t$ money injection must be fully absorbed by households in the form of an increase in cash holdings, $Q_{t}$.

To understand the impact of the rise in $Q_{t}$ on $R_{t}$, suppose for the moment that $\psi_{t}$ is constant. Since $P_{t}$ is predetermined, the rise in $Q_{t}$ corresponds to a rise in real balances. According to (3.31), the only way to induce households to increase $Q_{t} / P_{t}$ is for $R_{t}$ to fall. In practice we found that at the estimated values of the model parameters $\psi_{t}$ responds relatively little to a monetary shock so the previous argument captures the basic forces at work. As in standard limited participation models, the drop in $R_{t}$ arises because a subset of agents must absorb the full amount of an increase in the money supply. Unlike those models, here it is households that absorb the cash.

Finally, we note that, other things equal, the decline in the interest rate reduces marginal cost. This in turn helps the model generate an inertial response of inflation to a positive monetary policy shock.

With respect to the aggregate resource constraint, in the appendix we obtain an expression that relates aggregate consumption and investment to aggregate labor and capital services. ${ }^{25}$ In the appendix we also formally define an equilibrium for our model economy using a standard sequence-of-markets concept. In addition we discuss our computational

\footnotetext{
${ }^{25}$ Exact aggregation is not possible, since there is an additional term in this relationship having to do with the distribution of prices and wages. However, as shown by Yun (1996) and Erceg, Henderson and Levin (2000), that term does not appear in the linear approximation of the resource constraint about steady state. That is, to a first order approximation the aggregate resource constraint is expressed as a function involving only aggregate consumption, investment, labor and capital services.
} 
strategy for approximating that equilibrium. This involves taking a linear approximation about the non-stochastic steady state of the economy and using the solution method discussed in Christiano (2001).

\subsection{Functional Form Assumptions}

We assume that the functions characterizing utility are given by:

$$
\begin{gathered}
u(\cdot)=\log (\cdot) \\
z(\cdot)=\psi_{0}(\cdot)^{2} \\
v(\cdot)=\psi_{q} \frac{(\cdot)^{1-\sigma_{q}}}{1-\sigma_{q}}
\end{gathered} .
$$

In addition, investment adjustment costs are given by:

$$
F\left(i_{t}, i_{t-1}\right)=\left(1-S\left(\frac{i_{t}}{i_{t-1}}\right)\right) i_{t} .
$$

We restrict the function, $S$, to satisfy the following properties: $S(1)=S^{\prime}(1)=0$, and $\varkappa \equiv S^{\prime \prime}(1)>0$. Under our assumptions, in a nonstochastic steady state $F_{1}=1, F_{2}=0$, so that (3.33) implies $P_{k^{\prime}, t}=P_{k^{\prime}, t+1}=1$. It is easy to verify that the steady state of the model does not depend on the adjustment cost parameter, $\varkappa$. Of course, the dynamics of the model are influenced by $\varkappa$. Given our solution procedure, no other features of the $S$ function need to be specified for our analysis.

We impose two restrictions on the capital utilization function, $a\left(u_{t}\right)$. First, we require that $u_{t}=1$ in steady state. By (3.34), this is equivalent to $a^{\prime}=r^{k}$. Second, we assume $a(1)=0$. Under our assumptions, the steady state of the model is independent of $\sigma_{a}$, defined after (3.35). The dynamics do depend on $\sigma_{a}$. Given our solution procedure, we do not need to specify any other features of the function, $a$.

\section{Econometric Methodology}

In this section we discuss our methodology for estimating and evaluating our model. We partition the model parameters into three groups. The first group is composed of $\beta, \alpha, \delta, \psi_{\mathbf{0}}$, $\psi_{q}, \lambda_{w}$ and $\mu$. We set $\beta=1.03^{-0.25}$, which implies a steady state annualized real interest rate of 3 percent. Proceeding as in Christiano, Eichenbaum and Evans (1997), we set $\alpha=0.36$, which corresponds to a steady state share of capital income equal to roughly 36 percent. We set $\delta=0.025$, which implies an annual rate of depreciation on capital equal to 10 percent. This is roughly equal to the estimate reported in Christiano and Eichenbaum (1992). The 
parameter, $\psi_{\mathbf{0}}$, was chosen to imply a steady state value of $L$ equal to unity. Similarly, the parameter $\psi_{q}$ was set to ensure $Q / M=0.44$ in steady state. This is equal to the ratio of $M 1$ to $M 2$ at the beginning of our sample period. In fact the ratio of $M 1$ to $M 2$ exhibits a downward trend in the data. We redid our analysis using different values of $\psi_{q}$ and found that the only significant impact was on the estimated value of $\sigma_{q}$. The larger the assumed value of $\psi_{q}$, the smaller the elasticity of money demand required to match the data, i.e., the larger the implied value of $\sigma_{q}$. The parameter, $\mu$, was set to 1.017, which equals the postwar quarterly average gross growth rate of $M 2$. At our assumed parameter values, the steady state velocity of money is given by:

$$
\frac{P Y}{M}=(\mu-q)(1-\alpha) \frac{\beta}{\mu}=0.36 .
$$

This is slightly below the average value, 0.44 , of $M 2$ velocity in our sample.

We set the parameter, $\lambda_{w}$, to 1.05. In numerical simulations we found that our results are robust to perturbations in this parameter. ${ }^{26}$ Our specification of $z(\cdot)$ implies a Frisch labor supply elasticity equal to unity. This elasticity is low by comparison with the values assumed in the real business cycle literature. ${ }^{27}$ However, it is well within the range of point estimates reported in the labor literature (see Rotemberg and Woodford, 1999).)

The second group of parameters characterize monetary policy in the model. We choose these by requiring that the $\theta_{i}$ 's in (3.36) coincide exactly with our estimate of the dynamic response of the growth rate of money to a monetary policy shock. We proceed as in King and Watson (1996). In particular, we incorporate into the model the time series representation for $\mu_{t}$ implicit in the VAR, abstracting from non-monetary policy shocks. Let $c$ denote the 7 th column of the matrix $C$ in (2.2). Then, setting nonmonetary shocks to zero, the VAR in $(2.2)$ can be written

$$
Y_{t}=A_{1} Y_{t-1}+\ldots+A_{4} Y_{t-4}+c \varepsilon_{t} .
$$

Let $\tau$ denote a row vector with zeros and a single element containing unity in the location of $Y_{t}$ containing money growth, i.e., $\tau Y_{t}=\mu_{t}$. The stochastic process for money growth that is incorporated into the model is (4.1) with the understanding that $\tau Y_{t}$ is date $t$ money growth, and treating the other variables in $Y_{t}$ as information variables useful for forecasting future values of $\tau Y_{t}$. With this procedure, the moving average representation, (3.36), of money grow th incorporated into the model corresponds exactly to the moving average representation estimated in the data. Christiano, Eichenbaum and Evans (1998) describe a method for

\footnotetext{
${ }^{26}$ Holding fixed the other parameter values at their benchmark values reported below, we found that the impulse response functions implied by the model are insensitive to values of $\lambda_{w}$.

${ }^{27}$ For example, the Frisch elasticity implicit in the 'divisible labor' model in Christiano and Eichenbaum (1992) is roughly 2.5 percent.
} 
approximating this moving average representation in a parsimonious way. They find that it is not statistically significantly different from the moving average representation generated by a first order autoregression with coefficient roughly equal to 0.5 .

The third group of model parameters is:

$$
\gamma \equiv\left(\lambda_{f}, \xi_{w}, \xi_{p}, \sigma_{q}, \varkappa, b, \sigma_{a}\right)
$$

These were estimated by minimizing a measure of the distance between the model and empirical impulse response functions. Let $\Psi(\gamma)$ denote the mapping from $\gamma$ to the model impulse response functions, and let $\hat{\Psi}$ denote the corresponding empirical estimates. We include the first 25 elements of each response function. Our estimator of $\gamma$ is the solution to:

$$
J=\min _{\gamma}(\hat{\Psi}-\Psi(\gamma))^{\prime} V^{-1}(\hat{\Psi}-\Psi(\gamma)) .
$$

Here, $V$ is a diagonal matrix with the sample variances of the $\hat{\Psi}$ 's along the diagonal. These variances are the basis for the confidence intervals reported in Figure 1. So, with this choice of $V, \gamma$ is effectively chosen so that $\Psi(\gamma)$ lies as much as possible inside these confidence intervals.

\section{Empirical Results}

In this section we accomplish three things. First, we discuss the estimated parameter values. Second, we assess the ability of the estimated model to account for the impulse response functions discussed in section 2. Third, we document how the different features of the model contribute to its empirical performance.

\subsection{Parameter Estimates}

The row labeled 'benchmark' in Table 1 summarizes our point estimates of the parameters in the vector, $\gamma$. With the exception of $\sigma_{a}$, standard errors are reported in parentheses. ${ }^{28}$

\footnotetext{
${ }^{28}$ Here, we briefly describe how we computed the standard errors. Let $g(\hat{\gamma}, \hat{\psi})=0$ denote the first order condition associated with the solution to the minimization problem in (4.2). Here, $(\hat{\gamma}, \hat{\psi})$ are the estimators corresponding to the true values of the parameters, $\left(\gamma^{0}, \psi^{0}\right)$. The function, $g$, implicitly defines a mapping from $\psi^{0}$ to $\gamma^{0}$. The Taylor series expansion of this mapping about the true values of the parameters, is written, $g_{1}\left(\hat{\gamma}-\gamma^{0}\right)+g_{2}\left(\hat{\psi}-\psi^{0}\right)=0$, where $g_{1}$ and $g_{2}$ are the partial derivatives of $g$ with respect to $\gamma$ and $\psi$, evaluated at $\gamma^{0}, \psi^{0}$ (in practice, these are evaluated at the point estimates). Let $D=-g_{1}^{-1} g_{2}$. Then, $\sqrt{T}\left(\hat{\gamma}-\gamma^{0}\right) \underset{a}{\sim} N\left(0, D W D^{\prime}\right)$,
} 
We do not report a standard error for $\sigma_{a}$ because our estimation procedure drives that parameter towards zero, at which point the algorithm breaks down. As a result, we simply set $\sigma_{a}=0.01$ and optimized the estimation criterion over the remaining elements in $\gamma$. Setting $\sigma_{a}$ to a small value corresponds to the assumption that the adjustment cost function on capital utilization is very nearly linear. In section 3 we explained how low values of $\sigma_{a}$ dampen movements in the rental rate of capital, marginal costs and prices after a monetary policy shock.

We now discuss the remaining parameters in Table 1. First, our point estimate of $\xi_{w}$ implies that wage contracts last on average 3.3 quarters. Second, our point estimate of $\xi_{p}$ implies that price contracts last on average 2 quarters. Third, our estimate of $\xi_{w}$ is statistically significantly different from zero, while $\xi_{p}$ is only marginally so. This suggests that stickiness in nominal wages play an important role in the model's empirical performance, while stickiness in nominal prices does not. We explore this further below. Fourth, to interpret the point estimate of $\sigma_{q}$, it is useful to log-linearize the money demand function, (3.31), imposing (3.38):

$$
\hat{q}_{t}=-\frac{1}{\sigma_{q}}\left[\frac{R}{R-1} \hat{R}_{t}+\hat{\psi}_{t}\right] .
$$

The implied interest semi-elasticity of money demand is

$$
\frac{\partial \log q}{\partial R}=\frac{1}{4 \sigma_{q}(R-1)}
$$

holding $\hat{\psi}$ constant. Here, we have taken into account that the time period of the model is quarterly and the elasticity is measured with respect to the annualized rate of interest. Our parameter estimates imply that this elasticity is 1.05 , i.e., a one percentage point rise in the annualized rate of interest leads to a 1.05 percent reduction in real balances. This elasticity is considerably smaller than standard estimates reported for static money demand equations of this form. For example, the analogous number in Lucas (1988) is 8.0. We found that our estimate of $\sigma_{q}$ is driven primarily by the model's attempt to replicate the initial responses of the interest rate to a monetary policy shock (see below). Consequently, we interpret our interest semi-elasticity as pertaining to the short-run response of money demand. This elasticity is often estimated to be quite small (see Christiano, Eichenbaum and Evans, 1999).)

where $W$ is the (asymptotic) variance covariance matrix of $\sqrt{T}\left(\hat{\psi}-\psi^{0}\right)$. The standard errors reported in Table 1 are the relevant diagonal terms in $D W D^{\prime}$, after taking square roots and dividing by $\sqrt{T}$. 
Fifth, to interpret the point estimate of $\varkappa$, we log-linearize the household's Euler equation for investment, (3.33), about steady state to obtain:

$$
\hat{P}_{k^{\prime}, t}=\varkappa E_{t-1}\left\{\hat{\imath}_{t}-\hat{\imath}_{t-1}-\beta\left[\hat{\imath}_{t+1}-\hat{\imath}_{t}\right]\right\}
$$

so that:

$$
\hat{\imath}_{t}=\hat{\imath}_{t-1}+\frac{1}{\varkappa} \sum_{j=0}^{\infty} \beta^{j} E_{t-1} \hat{P}_{k^{\prime}, t+j} .
$$

According to this expression, $1 / \varkappa$ is the elasticity of investment with respect to a one percent increase in the current price of installed capital. ${ }^{29}$ While it is imprecisely estimated, our point estimate implies that this elasticity is equal to 0.28. A more persistent change in the price of capital induces a larger percentage change in investment. This is because adjustment costs induce agents to be forward looking. For example, a permanent one-percent change in the price of capital induces a $1 /[\varkappa(1-\beta)]=38$ percent change in investment. ${ }^{30}$

Sixth, our point estimate of the habit parameter $b$ is 0.63 . This is close to the point estimate of 0.7 reported in Boldrin, Christiano and Fisher (2001). Those authors argue that the ability of standard general equilibrium models to account for the equity premium and other asset market statistics is considerably enhanced by the presence of habit formation in preferences. Finally, the estimated value of $\lambda_{f}, 1.45$, is close to the value used in Rotemberg and Woodford (1995). Below, we discuss what features of the data drive the estimation criterion to this value. We show that the key role of $\lambda_{f}$ is to allow the model to account for the response of labor productivity to a monetary policy shock. The impulse response functions of the other variables in the model are insensitive to alternative values for $\lambda_{f}$ even values as low as 1.05 .

\subsection{Properties of the Estimated Model}

The impulse response functions of the estimated model are represented by the solid lines in Figure 1. A number of results are worth emphasizing here. First, the model does well at accounting for the dynamic response of the US economy to a monetary policy shock. With two exceptions, the model impulse responses lie within the two-standard deviation

\footnotetext{
${ }^{29}$ Recall that under our timing assumptions $E_{t-1} P_{k^{\prime}, t}=P_{k^{\prime}, t}$.

${ }^{30}$ The literature on Tobin's $q$ also reports empirical estimates of investment elasticities. It is difficult to compare these estimates with ours, however. This is because the Tobin's $q$ literature focuses on specifications in which only the current value of $\hat{P}_{k^{\prime}, t}$ enters into $\hat{\imath}_{t}$. From our perspective, the elasticities reported in this literature represent a combination of $s$ and the degree of persistence in $\hat{P}_{k^{\prime}, t}$.
} 
confidence interval computed from the data. The exceptions are that model output responds somewhat too strongly and profits too weakly in the first year. Second, the model succeeds in accounting for the inertial response of inflation. Indeed, there is no noticeable rise in inflation until roughly three years after the policy shock. Third, the model generates a very persistent response in output, with the peak response occurring after one year. After three years, the policy shock induces a cumulative rise in output of 3.3 percent. Over half of this increase occurs after the first year.

Figure 2 provides a different way of illustrating the last two observations. There, we display the response of the price level, the money stock and output in the model. Each is expressed as a percent of its level along the unshocked growth path. Notice how the money stock rises to its peak level by the third quarter after the shock and is roughly back to where it started by the middle of the third year. Despite the prolonged rise in the money stock, there is essentially no change in the price level. At the same time, there is a prolonged boom in output that lasts even after the boom in the money supply is over. The peak in output is almost twice as big as the peak in the money supply, with the former occurring one-half year after the latter.

Returning to Figure 1, notice that the model is able to account for the dynamic response of the interest rate to a monetary policy shock. Consistent with the data, an expansionary monetary policy shock induces a sharp decline in the interest rate which then returns to its pre-shock level within a year. It is interesting that a policy shock induces a more persistent effect on output than on the interest rate. Indeed, the peak effect on output occurs one quarter after the policy variable has returned to its steady state value. So, regardless of whether we measure policy by the money stock or the interest rate, the effects of a policy shock on aggregate variables persist beyond the effects on the policy variable itself. This reflects the strong internal propagation in the model.

Next note that, as in the data, the real wage rises by a small positive amount in response to the policy shock. Finally, consumption, investment and productivity all exhibit persistent, hump-shaped rises that are consistent with our estimates.

We now analyze how the various features of the model contribute to its performance. Figures 1 and 2 indicate that the money supply process in the data has two distinguishing features: the dynamic response to a policy shock is not smooth and the level of the money stock eventually returns to its pre-shock level. To verify that the model properties are not sensitive to these features of the money process, we solved the model assuming that the response of the growth rate of money, $\mu_{t}$, to a policy shock is governed by $\mu_{t}-\mu=$ $0.5\left(\mu_{t-1}-\mu\right)+\varepsilon_{t}$, i.e.,

$$
\mu_{t}-\mu=\varepsilon_{t}+0.5 \varepsilon_{t-1}+0.5^{2} \varepsilon_{t-2}+\ldots
$$

As noted above, Christiano, Eichenbaum and Evans (1998) argue that this is a good sta- 
tistical approximation to the estimated impulse response function for money growth. The first column of Figure 3 displays the properties of the model based on this representation of money growth. Notice that the dynamic behavior of this version of the model is similar that of the benchmark model.

Second, in our model the channel by which a policy shock affects aggregate quantities and prices operates via its impact on the future money supply. In particular, if the policy shock had no impact on $M_{t+s}, s \geq 2$, then prices, wages, output, consumption, investment and productivity would be unaffected at all dates. ${ }^{31}$ But, the interest rate would decline in the period of a policy shock. Through a sequence of numerical experiments, we found that the magnitude of the drop in $R_{t}$ depends primarily on the magnitude of the increase in $\mu_{t}$ and relatively little on the persistence properties of money. This reflects that the short-term anticipated inflation effects of a policy shock are small in our model. ${ }^{32}$

Third, sticky prices do not play a crucial role in the performance of the benchmark model. Column 2 in Figure 3 displays the impulse response functions for a version of the model in which we set $\xi_{p}=0$ and hold the remaining parameters at their benchmark values. With three exceptions, this version of the model does quite well. The exceptions are that output and real wages rise too much in response to the policy shock. In addition, inflation drops by too much. The latter result reflects the fall in marginal costs stemming from the drop in the interest rate.

A different way to assess the impact of sticky prices is to reestimate our model, subject to the constraint, $\xi_{p}=0$. The resulting point estimates are reported in Table 1 . The associated impulse response functions are not displayed because they are so similar to the ones in Column 2. Note from Table 1 that inference about $\xi_{w}$ is robust to imposing the restriction, $\xi_{p}=0$. The primary impact of this restriction on the point estimate is to reduce the estimate of $\lambda_{f}$, which falls from 1.46 to 1.29 . It is worth stressing that with $\xi_{p}=0$ the model still

\footnotetext{
${ }^{31}$ The argument is as follows. It is easy to verify that the time $t$ variables in the equations characterizing the equilibrium outcomes from period $t+1$ on are $c_{t}, i_{t}, P_{t}, W_{t}$ and $\bar{k}_{t}$. These variables, in conjunction with agents' views about $M_{t+s}, s \geq 2$, completely determine the equilibrium outcomes from $t+1$ on. (The variable, $M_{t+1}$, appears in these equations too, however, only as a product, $\mu_{t+1} M_{t+1}$ (see (3.20) and (3.37) for period $t+1$ ). The discussion in the text reflects that $\mu_{t+1} M_{t+1}=M_{t+2}$.) Our timing assumptions imply that $c_{t}, i_{t}, P_{t}, W_{t}$ and $\bar{k}_{t}$ are invariant to the realization of a period $t$ policy shock. The result follows from the assumption that $M_{t+s}, s \geq 2$ is also unaffected by a period $t$ policy shock.

${ }^{32}$ To see this, we considered two very different representations for money growth. In the first, a policy shock has no impact on the future money supply: $\mu_{t}=\mu+\varepsilon_{t}-\varepsilon_{t-1}$. In the second, the long-run impact on the money stock of a policy shock is ten times larger than the impact effect: $\mu_{t}-\mu=0.9\left(\mu_{t-1}-\mu\right)+\varepsilon_{t}$. We solved the model for the two different money processes and computed the impact effect on $R_{t}$ of setting $\varepsilon_{t}=0.15$. In the case of the first money process, $R_{t}$ drops 14 basis points, while in the second it drops 13 basis points.
} 
generates large, persistent increases in output and an inertial response in inflation. These observations substantiate the claim in the introduction that sticky prices play a limited role in accounting for the good fit of the benchmark model.

Fourth, sticky wages play a crucial role in the model's performance. Column 3 in Figure 3 displays the impulse response functions for a version of the model in which we set $\xi_{w}=$ 0 and hold the remaining parameters at their benchmark values. Note that the model's performance deteriorates dramatically. Inflation and the real wage surge in the aftermath of the shock. Output rises by only a small amount in the first period after the shock and then quickly returns to its pre-shock growth path. This result is reminiscent of Chari, Kehoe and McGrattan's (2000) finding that, in models where the only nominal rigidity is sticky prices, monetary policy shocks do not produce large, persistent movements in output. Also note that in this version of our model, consumption, investment, profits and productivity are essentially unaffected by the shock. When we attempted to estimate the model with $\xi_{w}=0$, the estimate of $\xi_{p}$ is driven to unity. Evidently, the estimation criterion prefers extreme degrees of price stickiness when there are no sticky wages.

Fifth, we now turn to the role played by the features of technology and preferences that distinguish our model from the textbook one-sector growth model. Column 1 in Figure 4 displays the impulse response functions for a version of the model in which we shut down variability in capital utilization, habit persistence in preferences and adjustment costs in investment. ${ }^{33}$ The remaining parameters are set at their benchmark values. Notice the dramatic deterioration in model performance. The response of inflation is immediate and strong: despite the presence of sticky wages and prices, the model fails to account for the small, inertial response of inflation to a policy shock. Similarly, output and investment initially overreact to the shock and exhibit little persistence. In addition, the model fails to reproduce the persistent drop in the interest rate, and predicts a counterfactual drop in the real wage. Finally, consumption, productivity and profits exhibit essentially no response to the policy shock. When we attempted to reestimate the parameters of this version of the model, $\xi_{p}$ and $\xi_{w}$ were driven to unity. This is a dramatic illustration of the claim made in the introduction that inference about nominal rigidities is sensitive to getting the real side of the model 'right'.

Columns 2, 3 and 4 of Figure 4 and Table 1 allow us to see how capacity utilization, adjustment costs and habit formation each contribute to the dynamics of our model. Column 2 indicates that shutting down variability in capital utilization reduces the magnitude and persistence in the response of the model's real variables. From Column 3, we see that when there are no adjustment costs in investment, a policy shock leads to a counterfactual surge in investment and output, and leaves consumption flat. Column 4 indicates that, in the absence

\footnotetext{
${ }^{33}$ We do this by setting $\sigma_{a}=1000, b=0, \varkappa=0.1$.
} 
of habit persistence, a policy shock leads to a counterfactual surge in consumption and output. As discussed in section 3, the surge in consumption with $b=0$ reflects households' response to the drop in the real rate of interest.

The previous results substantiate a claim that we made in the introduction. If we were only interested in inflation inertia and output persistence, the only change needed to the real side of the standard growth model is variable capital utilization. The role of habit persistence and investment adjustment costs is to allow the model to account for the response of other variables like consumption and investment to a monetary policy shock.

Next we note that inference about the model's structural parameters is sensitive to misspecifying the real side of the economy. For example, Table 1 indicates that, for all three cases discussed above, the estimated value of $\xi_{w}$ is higher than the benchmark estimate. This is most dramatic for the case in which we assume no adjustment costs in investment. Here, the estimated value of $\xi_{w}$ jumps from 0.70 to 0.89 ,so the estimated duration of a wage contract rises from a little over 3 quarters to a little over 2 years.

Sixth, we turn to the role played by the parameter, $\lambda_{f}$, in the performance of the model. Recall that as this parameter increases so does the degree of firms' market power. Column 1 in Figure 5 displays the impulse response functions for a version of the model in which we set $\lambda_{f}=1.05$ and hold the remaining parameters at their benchmark values. Notice that, productivity aside, this version of the model does at least as well as the benchmark model in accounting for the impulse response functions. The primary role of the higher value of $\lambda_{f}$ is to help the model account for the rise in productivity following a positive monetary policy shock. To see how this works, recall that the fixed cost, $\phi$, is set so that profits in steady state are zero. This implies that higher values of $\lambda_{f}$ correspond to higher values of $\phi$. Since $\phi$ enters additively in the resource constraint, it does not enter any of the Euler equations of the model. So, there are no substitution effects associated with changes in $\phi$. At the same time, the associated wealth effects are small. This is in part because we choose model parameter values so that steady state employment and capital utilization are always unity. These considerations imply that the percent changes in $L$ and in $Y+\phi$ (see (3.4)) associated with a given policy shock are roughly invariant to the magnitude of $\phi$. It follows that the percent increase in $Y$ and in $Y / L$ are increasing in $\lambda_{f}$.

Column 1 of Table 1 allows us to display the quantitative impact of $\lambda_{f}$ on the model's performance. There we display the dynamic response of the model when $\lambda_{f}$ is set to 1.05 and the other parameters are set to their benchmark values. With the exception of labor productivity, the impulse response functions of the model variables are basically unaffected. Table 1 reports the results of re-estimating the model subject to the constraint that $\lambda_{f}=$ 1.05. Note that inference about the values of the other parameters is robust to imposing this restriction. We conclude that the primary role of $\lambda_{f}$ is account for the behavior of labor 
productivity after a monetary policy shock.

Finally, we turn to the role of dynamic versus static price updating rules. To this end, we reestimated the benchmark model replacing the dynamic price-updating scheme, (3.7), by the static scheme, (3.6). The parameter estimates are reported in Table 1, and the corresponding impulse response functions are summarized in Column 2 of Figure 5. Three things are worth noting. First, this version of the model does about as well as the benchmark model in matching the estimated impulse response functions. Second, consistent with the discussion in section 3 , the degree of price and wage stickiness required to match the empirical impulse response functions is greater under the static price-updating scheme. For example, the average duration of wage contracts rises from 3.3 quarters to 5 quarters. Of course, once sampling uncertainty is taken into account, the differences are less dramatic. Third, the estimated degree of market power rises from 1.46 to 1.62 in the static price-updating version of the model. Again, taking into account sampling uncertainty the differences are not significant. So, while there are marginal improvements with the dynamic price-updating scheme, they are not critical to the model's performance.

\section{Conclusion}

We present a model embodying moderate amounts of nominal rigidities, which generates an inertial response in inflation and a persistent, hump-shaped, response in output after a positive monetary policy shock. In addition, the model generates hump-shaped responses in investment, consumption, employment, profits and productivity, and a small response in real wages. Finally, the interest rate and the money growth rate move in opposite directions after a monetary policy shock. The assumptions in the model rationalize a particular strategy for computing the analog responses in the data. The responses in the model and the data are similar.

Our model incorporates nominal rigidities in both wages and prices. Stickiness in nominal wages is crucial for the model's performance. Stickiness in prices plays a relatively small role.

We model nominal rigidities using the familiar Calvo framework. We think of this as a useful reduced form for capturing the factors that contribute to nominal sluggishness. Given the key role of wages in our results, this suggests the importance of modeling these factors in a structural manner and integrating them into dynamic, general equilibrium models. This conclusion is consistent with a long strand in the macroeconomics literature. 


\section{A. Appendix 1: The Linearized Aggregate Resource Constraint}

In this appendix we describe the linearized aggregate resource constraint. We use this in approximating the solution to the model. Let $Y^{*}$ denote the unweighted average of output in each intermediate good producer. Each producer faces the same factor prices and has the same production function, so that each has the same capital-labor ratio. As a result:

$$
Y^{*}=\int_{0}^{1} Y_{j} d j=\int_{0}^{1} k_{j}^{\alpha} L_{j}^{1-\alpha} d j=K^{\alpha} L^{1-\alpha} .
$$

To conserve on notation, we delete the time subscript, $t$. Also, $K$ and $L$ denote the aggregate amount of capital and of the homogeneous labor input, respectively:

$$
K=\int_{0}^{1} k_{j} d j, L=\int_{0}^{1} L_{j} d j
$$

Evidently, the unweighted sum of output of the intermediate goods producers can be represented as a function of aggregate capital and the aggregate amount of the homogeneous labor input. There are two reasons why this does not correspond to the expression for the aggregate resource constraint that we seek. First, the unweighted sum of output, $Y^{*}$, does not have any direct economic interpretation since it is a sum over differentiated intermediate inputs. Second, we would like to relate aggregate output, $Y$, to total labor,

$$
H \equiv \int_{0}^{1} h_{j} d j
$$

and not $L$, because $H$ corresponds to total labor as measured in the data.

Substituting out for $Y_{j}$ in (A.1) from the demand curve, (3.2):

$$
\begin{aligned}
Y^{*} & =\int_{0}^{1} Y_{j} d j=\int_{0}^{1}\left[\frac{P}{P_{j}}\right]^{\frac{\lambda_{f}}{\lambda_{f}-1}} Y d j \\
& =Y P^{\frac{\lambda_{f}}{\lambda_{f}-1}}\left(P^{*}\right)^{\frac{\lambda_{f}}{1-\lambda_{f}}} .
\end{aligned}
$$

Here, we have used (3.1) to replace the indicated weighted integral of $Y_{j}$ by $Y$. Also, $P^{*}$ is the indicated weighted average of the individual prices, where the weights differ from the ones used to construct $P$ in (3.3). So,

$$
Y=\left(\frac{P^{*}}{P}\right)^{\frac{\lambda_{f}}{\lambda_{f}-1}} Y^{*}=\left(\frac{P^{*}}{P}\right)^{\frac{\lambda_{f}}{\lambda_{f}-1}} K^{\alpha} L^{1-\alpha} .
$$


The variable, $Y$, corresponds to aggregate output. This is divided between consumption, investment and resources used up in capital utilization. This gives rise to the following resource constraint:

$$
a(u) \bar{k}+c+i \leq\left(\frac{P^{*}}{P}\right)^{\frac{\lambda_{f}}{\lambda_{f}-1}} K^{\alpha} L^{1-\alpha} .
$$

Our specification is complete, once (A.3) is expressed in terms of $H$ rather than $L$. Substituting out for $h_{j}$ in (A.2) using (3.25):

$$
\begin{aligned}
H & =\int_{0}^{1}\left[\frac{W_{j}}{W}\right]^{\frac{\lambda_{w}}{1-\lambda w}} L d j \\
& =L W^{\frac{\lambda_{w}}{\lambda_{w}-1}}\left(W^{*}\right)^{\frac{\lambda_{w}}{1-\lambda w}} \\
& =L\left(\frac{W}{W^{*}}\right)^{\frac{\lambda_{w}}{\lambda_{w}-1}}
\end{aligned}
$$

where

$$
W^{*}=\left[\int_{0}^{1} W_{j}^{\frac{\lambda w}{1-\lambda_{w}}} d j\right]^{\frac{1-\lambda_{w}}{\lambda_{w}}} .
$$

Note how $W^{*}$ differs from $W$ in $(3.26)$ by the weights used in the aggregation. Using the expression for $H$ to substitute out for $L$ in (A.3):

$$
a(u) \bar{k}+c+i \leq\left(\frac{P^{*}}{P}\right)^{\frac{\lambda_{f}}{\lambda_{f}-1}}\left(\frac{W^{*}}{W}\right)^{\frac{\lambda_{w}(1-\alpha)}{\lambda_{w}-1}} K^{\alpha} H^{1-\alpha} .
$$

This is our aggregate resource constraint. Note how the aggregation in effect introduces a 'Solow residual'-type term in the production function. As shown by Yun (1996) and Erceg, Henderson and Levin (2000), to a first order approximation, this 'Solow residual' is a constant. We briefly summarize their argument here for the dynamic price and wage updating schemes.

To establish this requires obtaining expressions for $W^{*} / W$ and $P^{*} / P$. The logic underlying (3.3) and (B.2) to obtain a expressions for $P_{t}$ and $W_{t}$ also works for $P_{t}^{*}, W_{t}^{*}$. Thus,

$$
P_{t}^{*}=\left[\left(1-\xi_{p}\right)\left(\tilde{P}_{t}\right)^{\frac{\lambda_{f}}{1-\lambda_{f}}}+\xi_{p}\left(\pi_{t-1} P_{t-1}^{*}\right)^{\frac{\lambda_{f}}{1-\lambda_{f}}}\right]^{\frac{1-\lambda_{f}}{\lambda_{f}}} .
$$


Dividing by $P_{t}$ :

$$
p_{t}^{*}=\left[\left(1-\xi_{p}\right)\left(\tilde{p}_{t}\right)^{\frac{\lambda_{f}}{1-\lambda_{f}}}+\xi_{p}\left(\frac{\pi_{t-1}}{\pi_{t}} p_{t-1}^{*}\right)^{\frac{\lambda_{f}}{1-\lambda_{f}}}\right]^{\frac{1-\lambda_{f}}{\lambda_{f}}}, p_{t}^{*}=\frac{P_{t}^{*}}{P_{t}}
$$

or, after linearizing about steady state:

$$
\hat{p}_{t}^{*}=\left(1-\xi_{p}\right) \hat{\tilde{p}}_{t}+\xi_{p}\left[\hat{\pi}_{t-1}-\hat{\pi}_{t}+\hat{p}_{t-1}^{*}\right] .
$$

Recall that a hat, $\because \hat{\prime}$, over a variable indicates percent deviation from steady state. Substituting (3.14) into this expression, we find

$$
\hat{p}_{t}^{*}=\xi_{p} \hat{p}_{t-1}^{*},
$$

which, assuming $\hat{p}_{\mathbf{0}}^{*}=0$, implies $\hat{p}_{t}^{*}=0$ for all $t$. This in turn implies $P_{t}^{*}=P_{t}$ for all $t$.

A similar argument can be used to conclude that, in the linear approximation to our model economy, $W_{t}^{*}=W_{t}$. The analog of expression (A.5) is:

$$
w_{t}^{*}=\left[\left(1-\xi_{w}\right)\left(\tilde{w}_{t}\right)^{\frac{\lambda_{w}}{1-\lambda_{w}}}+\xi_{w}\left(\frac{\pi_{t-1}}{\pi_{t}} \frac{w_{t-1}}{w_{t}} w_{t-1}^{*}\right)^{\frac{\lambda_{w}}{1-\lambda w}}\right]^{\frac{1-\lambda_{w}}{\lambda_{w}}}, w_{t}^{*}=\frac{W_{t}^{*}}{W_{t}}
$$

which, after linearization, reduces to:

$$
\hat{w}_{t}^{*}=\left(1-\xi_{w}\right) \hat{\tilde{w}}_{t}+\xi_{w}\left[\hat{\pi}_{t-1}-\hat{\pi}_{t}-\hat{w}_{t}+\hat{w}_{t-1}+\hat{w}_{t-1}^{*}\right] .
$$

Substituting (B.3) into this expression, we conclude

$$
\hat{w}_{t}^{*}=\xi_{w} \hat{w}_{t-1}^{*}
$$

implying $\hat{w}_{t}^{*}=0$ for all $t$, if, as we assume, $\hat{w}_{0}^{*}=0$.

We are now in a position to linearize the resource constraint, (A.4). We use the preceding argument to justify treating $P^{*} / P$ and $W^{*} / W$ as constants equal to unity in the linearization. Linearizing, and ignoring $P^{*} / P$ and $W^{*} / W$ :

$$
a^{\prime}(u) K \hat{u}_{t}+c \hat{c}_{t}+i \hat{\imath}_{t}=F_{K} K \hat{K}_{t}+F_{H} H \hat{H}_{t}
$$

where $F$ denotes the production function, $F(K, H)=K^{\alpha} H^{1-\alpha}$, and $F_{K}, F_{L}$ denote the derivatives of that function with respect to $K$ and $H$. Divide by $Y$ :

$$
a^{\prime}(u) \frac{K}{Y} \hat{u}_{t}+\frac{c}{Y} \hat{c}_{t}+\frac{i}{Y} \hat{\imath}_{t}=\alpha \hat{K}_{t}+(1-\alpha) \hat{H}_{t}
$$


Let

$$
s_{c}=\frac{c}{Y}, s_{i}=\frac{i}{Y}=\delta \frac{K}{Y}=\delta s_{k}, s_{k}=\frac{K}{Y}
$$

so that

$$
\left[\frac{1}{\beta}-(1-\delta)\right] \frac{K}{Y} \frac{Y}{c} \hat{u}_{t}+\hat{c}_{t}+\frac{s_{i}}{s_{c}} \hat{\imath}_{t}=\frac{\alpha}{s_{c}} \hat{K}_{t}+\frac{1-\alpha}{s_{c}} \hat{H}_{t},
$$

or

$$
\left[\frac{1}{\beta}-(1-\delta)\right] \frac{s_{K}}{s_{c}} \hat{u}_{t}+\hat{c}_{t}+\frac{\delta s_{k}}{s_{c}} \hat{\imath}_{t}=\frac{\alpha}{s_{c}} \hat{K}_{t}+\frac{1-\alpha}{s_{c}} \hat{H}_{t}
$$

where the steady state relation, $r^{k}=1 / \beta-(1-\delta)$ has been used. Equation (A.7) is the expression sought.

\section{B. Appendix 2: Approximate Model Solution}

To approximate the solution to our model, we first linearize the Euler equations and various model identities about the steady state of the model in which the aggregate shock (but, not the idiosyncratic shocks) is held at its unconditional mean. We then solve the resulting system using a combination of the undetermined coefficients method described in Christiano (2001) and the method in Anderson and Moore (1985).

\section{B.1. The Linearized System}

The 13 variables in our system are contained in a variable, $z_{t}$ :

$$
z_{t}=\left[\begin{array}{lllllllllllll}
\hat{\pi}_{t} & \hat{\bar{q}}_{t} & \hat{\bar{w}}_{t} & \hat{c}_{t} & \hat{\bar{K}}_{t+1} & \hat{m}_{t} & \hat{L}_{t} & \hat{R}_{t} & \hat{H}_{t} & \hat{u}_{c t} & \hat{P}_{k^{\prime}, t} & \hat{I}_{t} & \hat{K}_{t}
\end{array}\right]^{\prime}
$$

Recall, $\hat{x}_{t}=\left(x_{t}-x\right) / x$, where $x$ is the value of $x_{t}$ in nonstochastic steady state. Also, $\bar{q}_{t}=Q_{t} / P_{t-1}$ and $\bar{w}_{t}=W_{t} / P_{t-1}$. We solve for the dynamics of these variables using thirteen Euler and other equations. Of these, the first two are (3.15) (5.1). The third equation is one that involves the aggregate wage rate. To derive this, it is convenient to define:

$$
\tilde{w}_{t}=\frac{\tilde{W}_{t}}{W_{t}}, w_{t}=\frac{W_{t}}{P_{t}}
$$

Note that $\hat{\tilde{w}}_{t}+\hat{w}_{t}$ corresponds to the percentage deviation of the household's real wage rate from its nonstochastic steady state value. Also, $\widehat{\bar{w}}_{t}=\hat{w}_{t}-\hat{\pi}_{t}$. Linearizing (3.29) about steady 
state making use of (3.25) and rearranging we obtain:

$$
\begin{aligned}
\hat{\tilde{w}}_{t}+\hat{w}_{t}= & \sum_{l=1}^{\infty}\left(\beta \xi_{w}\right)^{l}\left(\hat{\pi}_{t+l}-\hat{\pi}_{t+l-1}\right) \\
& +\frac{\left(1-\beta \xi_{w}\right)\left(\lambda_{w}-1\right)}{2 \lambda_{w}-1} \sum_{j=l}^{\infty}\left(\beta \xi_{w}\right)^{j}\left[\hat{L}_{t+j}+\frac{\lambda_{w}}{\lambda_{w}-1} \hat{w}_{t+j}-\hat{\psi}_{t+j}\right] .
\end{aligned}
$$

When the wage rate is updated according to (3.27) the first difference of inflation is replaced by the level of inflation in (B.1). It follows that under (3.28), households have a smaller incentive to front-load an increase in the wage rate in response to expected transitory rises in the inflation rate. This feature helps the model account for the slow, persistent rise in inflation after a monetary shock.

Analogous to (3.13), (3.26) can be written as:

$$
W_{t}=\left[\left(1-\xi_{w}\right)\left(\tilde{W}_{t}\right)^{\frac{1}{1-\lambda_{w}}}+\xi_{w}\left(\pi_{t-1} W_{t-1}\right)^{\frac{1}{1-\lambda w}}\right]^{1-\lambda_{w}}
$$

Dividing by $P_{t}$ and linearizing about steady state, we obtain:

$$
\left(1-\xi_{w}\right) \hat{\tilde{w}}_{t}=\xi_{w} \hat{w}_{t}-\xi_{w}\left(\hat{w}_{t-1}-\left(\hat{\pi}_{t}-\hat{\pi}_{t-1}\right)\right) .
$$

Combining this expression with (B.1) and rearranging we obtain:

$$
\begin{aligned}
0= & \hat{w}_{t-1}-\frac{b_{w}\left(1+\beta \xi_{w}^{2}\right)-\lambda_{w}}{b_{w} \xi_{w}} E_{t-1} \hat{w}_{t}+\beta E_{t-1} \hat{w}_{t+1} \\
& +E_{t-1}\left[\beta\left(\pi_{t+1}-\pi_{t}\right)-\left(\pi_{t}-\pi_{t-1}\right)\right]+\frac{1-\lambda_{w}}{b_{w} \xi_{w}} E_{t-1} \hat{\psi}_{t}-\frac{1-\lambda_{w}}{b_{w} \xi_{w}} E_{t-1} \hat{L}_{t},
\end{aligned}
$$

where

$$
b_{w}=\frac{2 \lambda_{w}-1}{\left(1-\xi_{w}\right)\left(1-\beta \xi_{w}\right)} .
$$

After taking into account $\hat{w}_{t}=\hat{\bar{w}}_{t}+\hat{\pi}_{t}$, this represents our third equation. When the wage rate is updated according to (3.27), the first difference of inflation is replaced by the level of inflation in the preceding expression.

Our fourth equation is the linearized version of (3.24):

$$
E_{t}\left\{\hat{\psi}_{t+1}+\hat{R}_{t+1}-\hat{\pi}_{t+1}-\hat{\psi}_{t}\right\}=0 .
$$


We obtain our fifth equation after multiplying (3.32) on both sides by $P_{k^{\prime}, t}$, and linearizing the result: ${ }^{34}$

$$
\begin{aligned}
0= & E_{t-1}\left\{-\hat{P}_{k^{\prime}, t}-\hat{\psi}_{t}+\hat{\psi}_{t+1}+(1-\beta(1-\delta))\left[\hat{\bar{w}}_{t+1}-\hat{\pi}_{t+1}+\hat{R}_{t+1}+\hat{L}_{t+1}-\hat{K}_{t+1}\right]\right. \\
& \left.+\beta(1-\delta) \hat{P}_{k^{\prime}, t+1}\right\}
\end{aligned}
$$

Here, we have made the substitution,

$$
\hat{r}_{t+1}^{k}=\hat{w}_{t+1}+\hat{R}_{t+1}+\hat{L}_{t+1}-\hat{K}_{t+1},
$$

and we taken into account the steady state condition, $r^{k}=a^{\prime}$. The sixth equation is the linearization of the aggregate resource constraint, (A.7). The seventh equation is the linearization of the loan market clearing condition, (3.37):

$$
\mu m\left(\hat{\mu}_{t}+\hat{m}_{t}\right)-q\left(\hat{\bar{q}}_{t}-\hat{\pi}_{t}\right)-w L\left(\hat{\bar{w}}_{t}-\hat{\pi}_{t}+\hat{L}_{t}\right)=0
$$

The eight equation linearizes the definition of money growth, $\mu_{t-1}=M_{t} / M_{t-1}$ :

$$
\hat{\mu}_{t-1}+\hat{m}_{t-1}-\hat{\pi}_{t}-\hat{m}_{t}=0 \text {. }
$$

In our analysis we adopted a slightly generalized version of the habit model displayed in (3.19), one in which utility of consumption is a function of $c_{t}-H_{t}$, with $H_{t}=\psi H_{t-1}+b c_{t-1}$. As a result,

$$
\hat{H}_{t}-\chi \hat{H}_{t-1}-(1-\chi) \hat{c}_{t-1}=0
$$

We found that $\chi=0$ is adequate for our purposes and only report results for this case in the text. Still, this latter forms our ninth equation. With our (generalized) specification of utility the multiplier, $\hat{\psi}_{c, t}$ must satisfy the following relation, our tenth:

$$
E_{t-1}\left\{-\beta \chi \hat{\psi}_{c, t+1}+\tilde{\sigma}_{c}^{i}\left[\hat{c}_{t}-\frac{b}{1-\chi} \hat{H}_{t}\right]-(b+\chi) \beta \tilde{\sigma}_{c}^{i}\left[\hat{c}_{t+1}-\frac{b}{1-\chi} \hat{H}_{t+1}\right]+\hat{\psi}_{c, t}\right\}=0
$$

where

$$
\tilde{\sigma}_{c}^{i}=\frac{1-\chi}{1-\chi-b} \frac{1-\beta \chi}{1-\beta \chi-\beta b} .
$$

This relationship can be derived after some algebra, after noting (3.22).

\footnotetext{
${ }^{34}$ This multiplication is valid because $P_{k^{\prime}, t}$ is not a function of the realization of the current aggregate money growth rate.
} 
Our eleventh and twelfth equations are obtained by linearizing (3.33) and (3.21), respectively:

$$
\begin{gathered}
E_{t-1} \hat{P}_{k^{\prime}, t}=s E_{t-1}\left\{\hat{\imath}_{t}-\hat{\imath}_{t-1}-\beta\left[\hat{\imath}_{t+1}-\hat{\imath}_{t}\right]\right\} . \\
\widehat{\bar{k}}_{t+1}=(1-\delta) \hat{\bar{k}}_{t}+\delta \hat{\imath}_{t} .
\end{gathered}
$$

Our thirteenth and final relationship linearizes (3.34):

$$
E_{t-1}\left\{\hat{K}_{t}-\hat{\bar{K}}_{t}-\frac{1}{\sigma_{\tilde{\delta}}}\left(\hat{\bar{w}}_{t}-\hat{\pi}_{t}+\hat{R}_{t}+\hat{L}_{t}-\hat{K}_{t}\right)\right\}=0 .
$$

\section{B.2. Solving the Linearized System}

The thirteen equations in the previous subsection may be written in the following format:

$$
\mathcal{E}_{t}\left\{\alpha_{0} z_{t+1}+\alpha_{1} z_{t}+\alpha_{2} z_{t-1}+\beta_{0} \omega_{t+1}+\beta_{1} \omega_{t}\right\}=\underset{\sim}{0}
$$

where $\alpha_{i}$ are $13 \times 13$ matrices, $\beta_{i}$ is $13 \times N, i=0,1$ and 0 is a $13 \times 1$ vector of zeros. Here, $\omega_{t}$ is an $N$-dimensional vector stochastic process with representation:

$$
\omega_{t}=\rho \omega_{t-1}+\tilde{\varepsilon}_{t},
$$

where $\tilde{\varepsilon}_{t}$ is white noise. Expression (B.6) is (4.1) expressed in first order autoregressive form. The vector, $\omega_{t}$, contains the money growth rate and various lags, as well as the other variables. Because (4.1) is a 10-variable, 4-lag vector autoregression, it follows that $N=40$. Columns in $\beta_{0}$ and $\beta_{1}$ pertaining to components of $\omega_{t}$ other than current money growth are zero. Finally, $\mathcal{E}_{t}$ is the expectation operator, which reflects the timing assumptions on the thirteen equations above. In particular, in the first, third, fifth, tenth, eleventh and thirteen equations, the conditional expectation is $E_{t-1}$ while it is $E_{t}$ in the others.

Let $z_{t}=A z_{t-1}+B \omega_{t}$, where $A$ and $B$ are $13 \times 13$ and $13 \times N$ matrices, respectively. A solution is an $A$ with eigenvalues less than unity in absolute value and a $B$ which have the property that (B.5) is satisfied for all possible $z_{t-1}$ and $\omega_{t}$. To see what this requires, substitute the solution into (B.5) to obtain

$$
\alpha(A) z_{t-1}+\mathcal{E}_{t} F \omega_{t}=0
$$

where $\alpha(A)=\alpha_{0} A^{2}+\alpha_{1} A+\alpha_{2} I$ and $F$ is a function of $A$ and $B$. Write $\mathcal{E}_{t} F \omega_{t}=\tilde{F} \omega_{t}$, where the entries corresponding to the 10 date $t$ variables in the first, third, fifth, tenth, eleventh and thirteen rows of $\tilde{F}$ are zero. A solution is found by choosing an $A$ with eigenvalues less than unity in absolute value so that $\alpha(A)=0_{13 \times 13}$ and a $B_{13 \times N}$ matrix that satisfies the same zero restrictions as $\tilde{F}$,such that $\tilde{F}=0_{13 \times N}$ In the model parameterizations reported in the analysis, the $A$ and $B$ matrices that satisfy these conditions are unique. 


\section{References}

[1] Anderson, Gary S. and George Moore, 1985, 'A Linear Algebraic Procedure for Solving Linear Perfect Foresight Models,' Economic Letters, 17, 247-52.

[2] Ball, Laurence, 1994, 'Credible Disinflation with Staggered Price Setting, American Economic Review, Vol. 84, March, pages 282 - 289.

[3] Basu, Susanto, and John Fernald, 1994, Constant returns and small markups in US manufacturing, Working paper, International Finance Discussion Paper No. 483, Board of Governors of the Federal Reserve System.

[4] Boldrin, Michele, Christiano, Lawrence J. and Jonas Fisher, 2001, 'Habit Persistence, Asset Returns and the Business Cycle,' American Economic Review, 91(1), March, pages 149-166.

[5] Burnside, Craig and Martin Eichenbaum, 1996, 'Factor-Hoarding and the Propagation of Business Cycle Shocks', American Economic Review, 86(5), December, pages 1154-74.

[6] Calvo, Guillermo, 1983, 'Staggered Prices and in a Utility-Maximizing Framework, Journal of Monetary Economics, 12(3): 383-98.

[7] Casares, Miguel and Bennett T. McCallum, 2000, 'An Optimizing IS-LM Framework with Endogenous Investment,' National Bureau of Economic Research Working Paper \#7908.

[8] Chari, V.V., Kehoe, Patrick and Ellen McGrattan, 2000, 'Sticky Price Models of the Business Cycle: Can the Contract Multiplier Solve the Persistence Problem?', Econometrica, 68(5), September, pages 1151-79.

[9] Chari, V.V., Christiano, Lawrence J. and Martin Eichenbaum, 1995, 'Inside Money, Outside Money and Short Term Interest Rates', Journal of Money, Credit and Banking, 27(4), Part 2 Nov., pages 1354-86.

[10] Christiano, Lawrence J. and Martin Eichenbaum, 1992, 'Current RealBusiness-Cycle Theories and Aggregate Labor-Market Fluctuations', American Economic Review, 82(3), June, pages 430-50.

[11] Christiano, Lawrence J., Eichenbaum, Martin and Charles Evans, 1998, Modeling Money, NBER working paper 6371. 
[12] Christiano, Lawrence J., Eichenbaum, Martin and Charles Evans, 1997, 'Sticky Price and Limited Participation Models: A Comparison', European Economic Review,Vol. 41, No. 6, June, pp. 1173-1200.

[13] Christiano, Lawrence J., Eichenbaum, Martin and Charles Evans, 1999, 'Monetary Policy Shocks: What Have We Learned and to What End?', Handbook of Macroeconomics, Vol. 1A, , eds.Michael Woodford and John Taylor, Amsterdam; New York and Oxford: Elsevier Science, North-Holland.

[14] Cooley, Thomas F. and Gary D. Hansen, 1989, 'The Inflation Tax in a Real Business Cycle Model', American Economic Review, Vol. 79, No. 4, pages $733-748$.

[15] Dotsey,Michael, King, Robert, G. and Alexander L. Wolman, 1999, 'StateDependent Pricing and the General Equilibrium Dynamics of Money and Output', Quarterly Journal of Economics, 114(2), May, pages 655-90.

[16] Edge, Rochelle M., 2000, 'Time-to-Build, Time-to-Plan, Habit-Persistence, and the Liquidity Effect,' International Finance Discussion Papers number 673 , July.

[17] Erceg, Christopher, J., Henderson, Dale, W. and Andrew T. Levin, 2000, 'Optimal Monetary Policy with Staggered Wage and Price Contracts', Journal of Monetary Economics, 46(2), October, pages 281-313.

[18] Fuhrer, Jeffrey, 2000, 'Habit Formation in Consumption and Its Implications for Monetary-Policy Models', American Economic Review, 90(3), June, pages 367-90.

[19] Gali, Jordi, and Mark Gertler, 1999, 'Inflation dynamics: A structural econometric analysis,' Journal of Monetary Economics, 44, pp. 195-222.

[20] Hall, Robert, 1988, 'The Relation Between Price and Marginal Cost in U.S. Industry,' Journal of Political Economy, 96 (5): 921-47.

[21] Ireland, Peter, 1997, “ A Small, Structural, Quarterly Model for Monetary Policy Evaluation, Carnegie Rochester Conference Series on Public Policy, 47 , pages $83-108$. 
[22] Kim, Jinill, 2000, 'Constructing and Estimating a Realistic Optimizing Model of Monetary Policy', Journal of Monetary Economics, 45(2), April 2000, pages $329-59$.

[23] King, Robert G. and Mark Watson, 1996, Money, Prices, Interest Rates and the Business Cycle', Review of Economics and Statistics, 78(1), February, pages $35-53$.

[24] King, Robert G. and Sergio Rebelo, 1999, 'Resuscitating Real Business Cycles,' Handbook of Macroeconomics, Vol. 1A, eds.Michael Woodford and John Taylor, Amsterdam; New York and Oxford: Elsevier Science, NorthHolland.

[25] Leeper, Eric and Christopher A. Sims, (1994), 'Toward a Modern Macroeconomic Model Usable for Policy Analysis', Fischer, Stanley and Julio J. Rotemberg, eds. NBER Macroeconomics Annual 1994, Cambridge and London: MIT Press, 1994, pages 81-118.

[26] Lucas, Robert E., Jr., 1988, 'Money Demand in the United States: A Quantitative Review', Carnegie-Rochester Conference Series on Public Policy, Vol. 29 , pages $137-167$.

[27] Mankiw, N. Gregory, 2001, 'The Inexorable and Mysterious Tradeoff Between Inflation and Unemployment', forthcoming, Economic Journal.

[28] McCallum, Bennett, and Edward Nelson, 1998, 'Nominal Income Targeting in an Open-Economy Optimizing Model,' National Bureau of Economic Research Working Paper number 6675.

[29] Rotemberg, Julio J. and Michael Woodford, M. 1995, Dynamic General Equilibrium Models with Imperfectly Competitive Product Markets. In Frontiers of Business Cycle Research, ed. Thomas F. Cooley, pp. 243-293. Princeton: Princeton University Press.

[30] Rotemberg, Julio J. and Michael Woodford, 1997, 'An Optimization-Based Econometric Framework for the Evaluation of Monetary Policy', National Bureau of Economic Research Macroeconomics Annual.

[31] Rotemberg, Julio J. and Michael Woodford, 1999, 'The Cyclical Behavior of Prices and Costs', Handbook of Macroeconomics, Vol. 1A, , eds.Michael 
Woodford and John Taylor, Amsterdam; New York and Oxford: Elsevier Science, North-Holland.

[32] Sbordone, Argia, 2000, 'An Optimizing Model of U.S. Wage and Price Dynamics,' manuscript, Rutgers University.

[33] Sims, Christopher A., 1994, 'A Simple Model for the Determination of the Price Level and the Interaction of Monetary and Fiscal Policy,' Economic Theory, 4, 381-399.

[34] Sims, Christopher A., 1998, 'Stickiness,' Carnegie Rochester Conference Series on Public Policy; 49(0), December, pages 317-56.

[35] Sims, Christopher A., and Tao Zha, 1999, 'Error Bands for Impulse Responses', Econometrica, 67(5), September, pages 1113-55.

[36] Walsh, Carl E., 1998, Monetary Theory and Policy, Cambridge and London: MIT Press, pages 528.

[37] Woodford, Michael, 1994, 'Monetary Policy and Price Level Determinacy in a Cash-In-Advance Economy,' Economic Theory, 4, 345-389.

[38] Woodford, Michael, 1996, 'Control of the Public Debt: A Requirement for Price Stability', NBER Working Paper 5684.

[39] Yun, Tack, 1996, 'Nominal Price Rigidity, Money Supply Endogeneity, and Business Cycles,' Journal of Monetary Economics, 37(2): 345 - 370.

[40] Zbaracki, Mark J., Mark Ritson, Daniel Levy, Shantanu Dutta, and Mark Bergen, 2000, 'The Managerial and Customer Costs of Price Adjustment: Direct Evidence from Industrial Markets,' manuscript, Wharton School, University of Pennsylvania. 


\begin{tabular}{|c|c|c|c|c|c|c|c|}
\hline \multicolumn{8}{|c|}{ TABLE 1: ESTIMATED PARAMETER VALUES } \\
\hline Model & $\overline{\lambda_{f}}$ & $\overline{\xi_{w}}$ & $\overline{\xi_{p}}$ & $\sigma_{q}$ & $\varkappa$ & $\bar{b}$ & $\overline{\sigma_{a}}$ \\
\hline Benchmark & $\begin{array}{l}1.46 \\
(.16)\end{array}$ & $\begin{array}{l}.70 \\
(.07)\end{array}$ & $\begin{array}{l}.50 \\
(.23)\end{array}$ & $\begin{array}{l}9.66 \\
(.78)\end{array}$ & $\begin{array}{l}3.60 \\
(2.24)\end{array}$ & $\begin{array}{l}.63 \\
(.14)\end{array}$ & .01 \\
\hline Fixed $\lambda_{f}$ & 1.05 & $\begin{array}{l}.73 \\
(.07)\end{array}$ & $\begin{array}{l}.40 \\
(.21)\end{array}$ & $\begin{array}{l}9.88 \\
(.78)\end{array}$ & $\begin{array}{l}2.92 \\
(1.74)\end{array}$ & $\begin{array}{l}.57 \\
(.16)\end{array}$ & .01 \\
\hline Fixed $\xi_{p}$ & $\begin{array}{l}1.29 \\
(.10)\end{array}$ & $\begin{array}{l}.69 \\
(.06)\end{array}$ & 0 & $\begin{array}{l}8.03 \\
(.96)\end{array}$ & $\begin{array}{l}4.30 \\
(2.79)\end{array}$ & $\begin{array}{l}.64 \\
(.11)\end{array}$ & .01 \\
\hline No habit & $\begin{array}{l}1.25 \\
(.09)\end{array}$ & $\begin{array}{r}.80 \\
(.05)\end{array}$ & $\begin{array}{r}.34 \\
(.28)\end{array}$ & $\begin{array}{l}9.38 \\
(.69)\end{array}$ & $\begin{array}{l}1.18 \\
(.49)\end{array}$ & 0 & .01 \\
\hline $\begin{array}{l}\text { No Variable } \\
\text { Capital Utilization }\end{array}$ & $\begin{array}{l}2.64 \\
(.43)\end{array}$ & $\begin{array}{l}.77 \\
(.19)\end{array}$ & $\begin{array}{l}.54 \\
(.21)\end{array}$ & $\begin{array}{l}9.01 \\
(.75)\end{array}$ & $\begin{array}{c}10.30 \\
(8.25)\end{array}$ & $\begin{array}{l}.78 \\
(.07)\end{array}$ & 1000 \\
\hline $\begin{array}{l}\text { No Adjustment } \\
\text { Costs in Investment }\end{array}$ & $\begin{array}{l}1.24 \\
(.09)\end{array}$ & $\begin{array}{r}.89 \\
(.05)\end{array}$ & $\begin{array}{l}.42 \\
(.19)\end{array}$ & $\begin{array}{l}9.44 \\
(.67)\end{array}$ & .1 & $\begin{array}{c}45 \\
(.56)\end{array}$ & .01 \\
\hline $\begin{array}{l}\text { Unconditional } \\
\text { Indexation }\end{array}$ & $\begin{array}{l}1.62 \\
(.22) \\
\end{array}$ & $\begin{array}{r}.82 \\
(.33) \\
\end{array}$ & $\begin{array}{r}.61 \\
(.21) \\
\end{array}$ & $\begin{array}{l}9.77 \\
(.76) \\
\end{array}$ & $\begin{array}{l}2.95 \\
(1.76) \\
\end{array}$ & $\begin{array}{r}.61 \\
(.14) \\
\end{array}$ & .01 \\
\hline
\end{tabular}



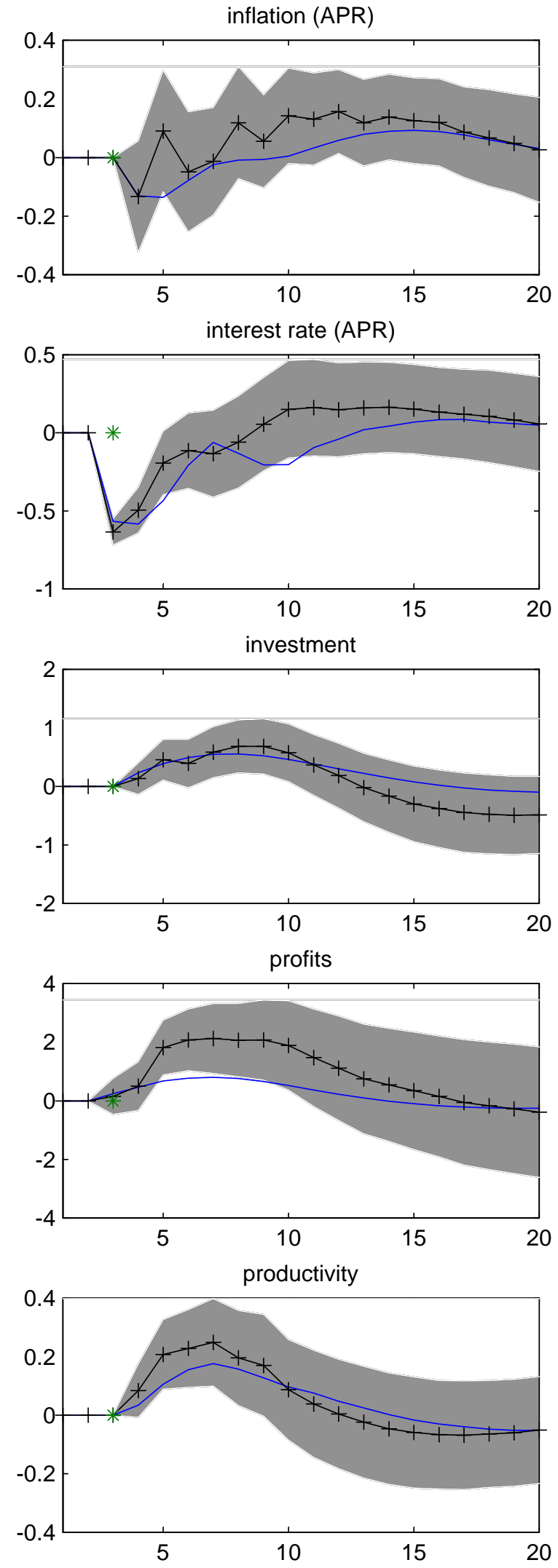
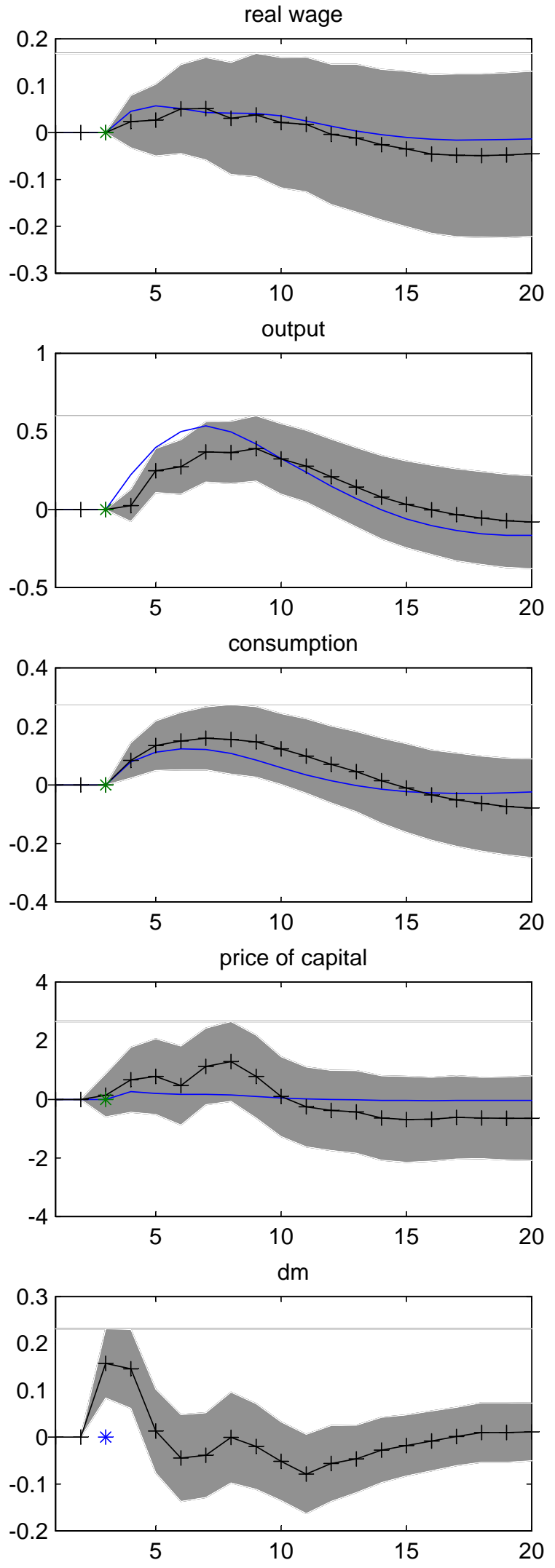
Figure 2: Price Level, Output and Money Stock

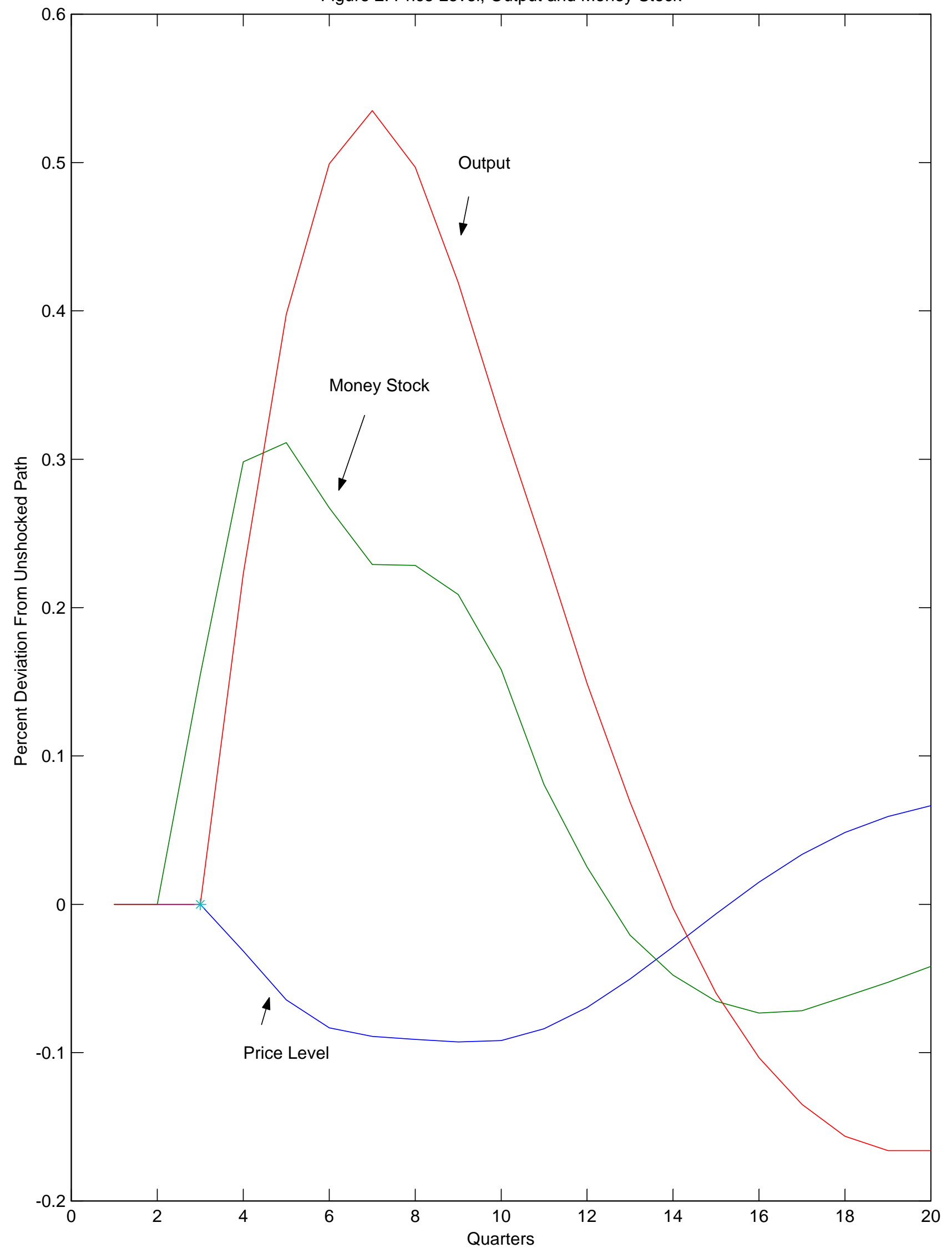



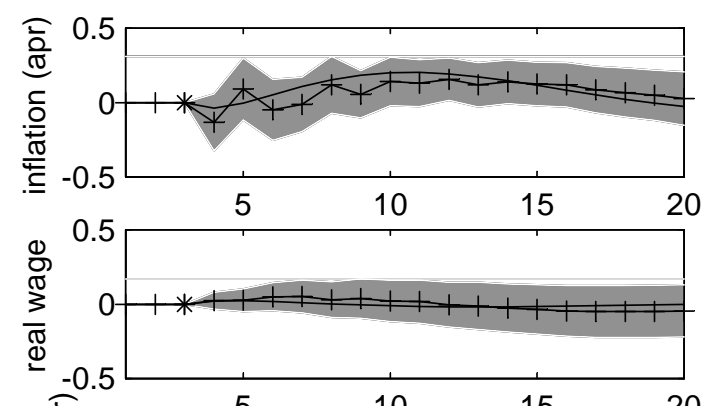

0
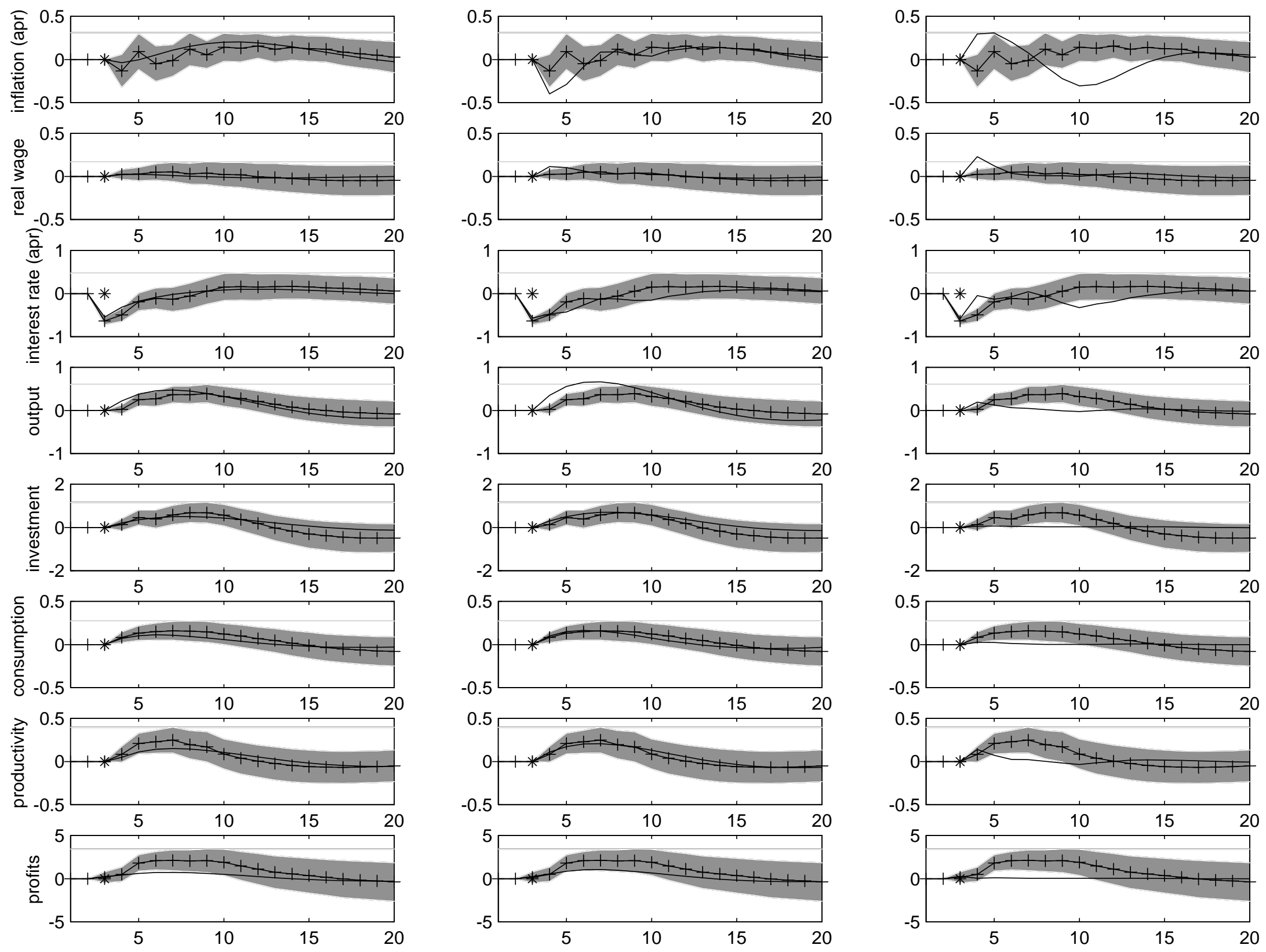

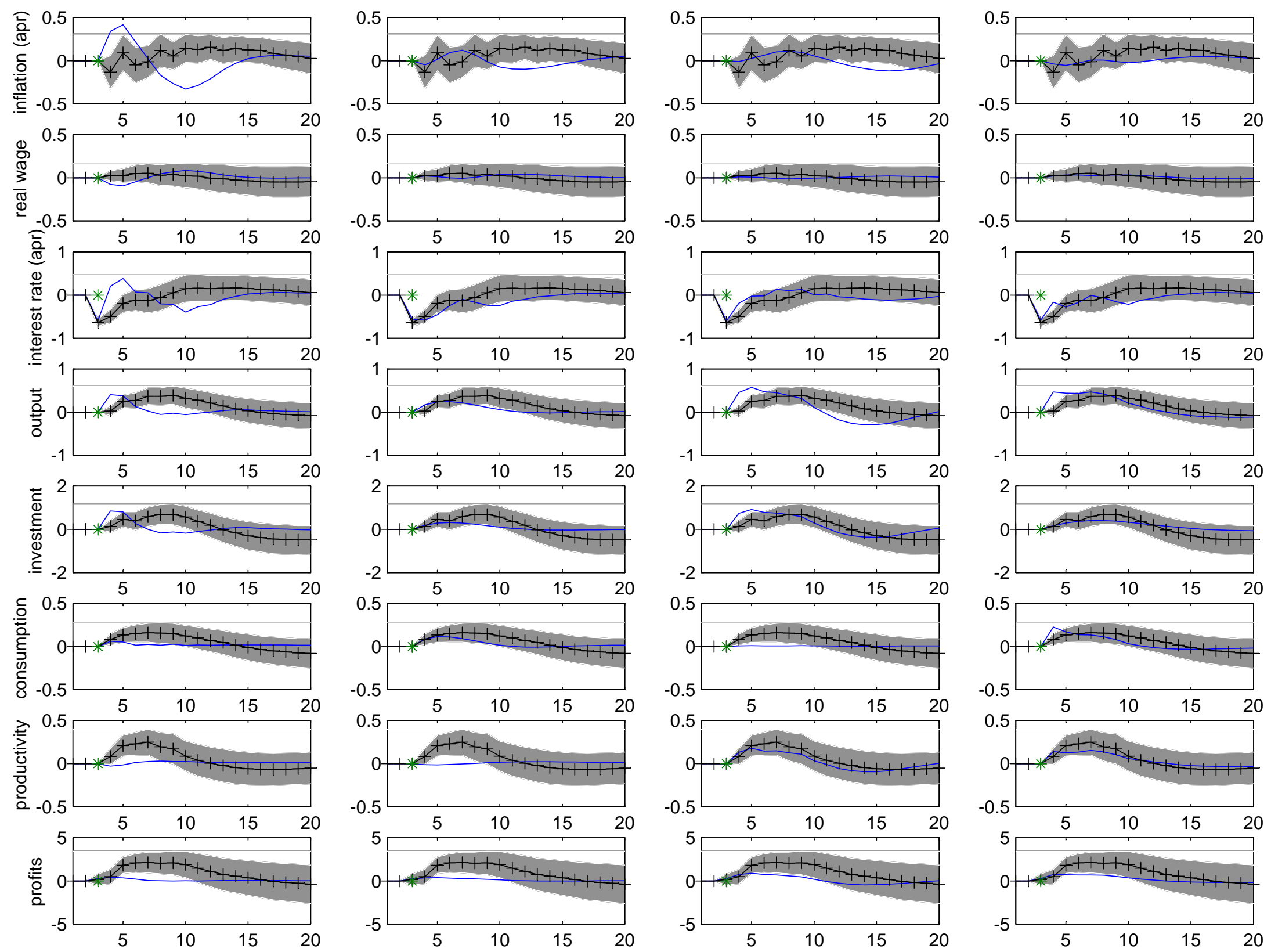

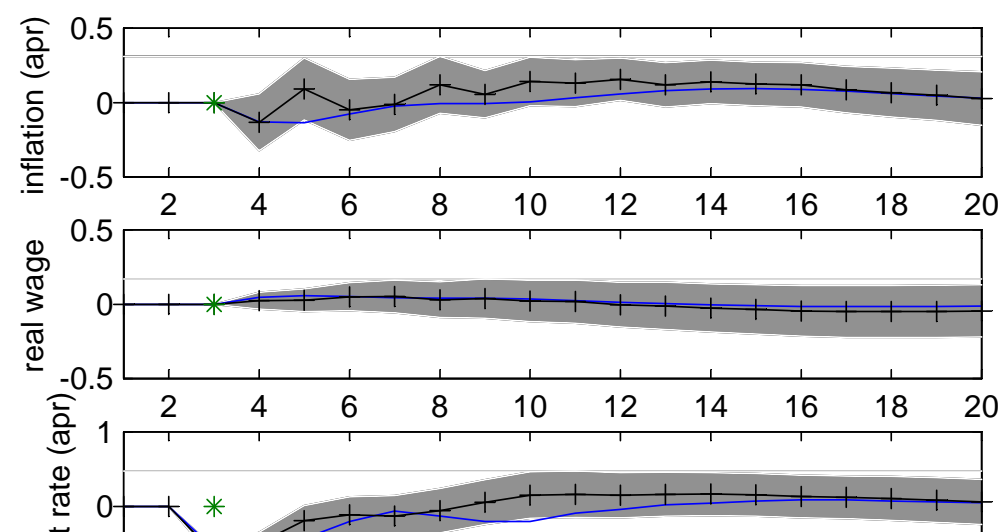

$\stackrel{\pi}{\pi} 0$
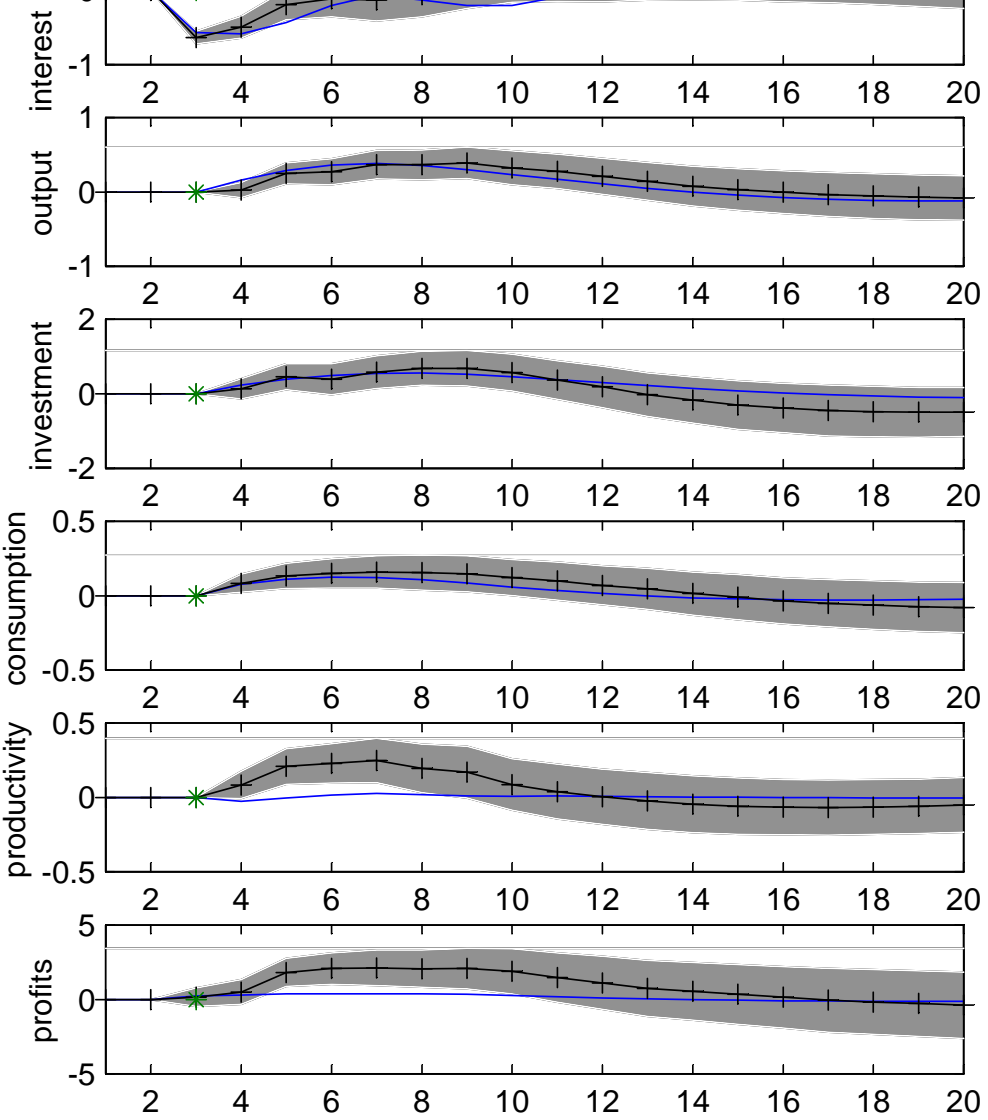
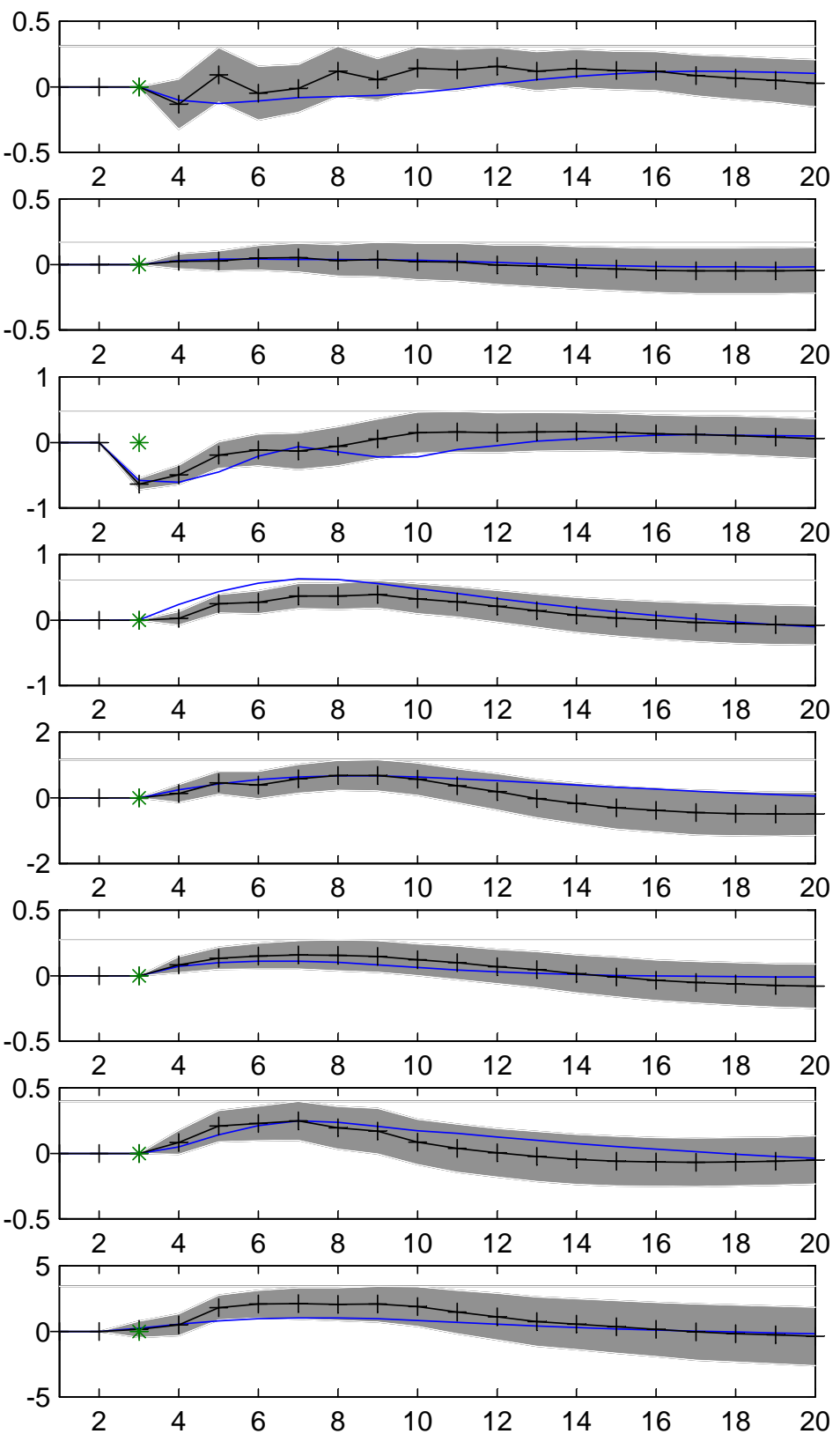